\title{
Extraction of non-noble metal columbite-tantalite as a highly efficient electrocatalyst for water splitting
}

Patrick Bacirhonde ( $\sim$ bacipatrick@jbnu.ac.kr)

Jeonbuk National University https://orcid.org/0000-0001-7134-5696

Nelson Dzade

Cardiff University

Carmen Chalony

Jeonbuk National University

Jeesoo Park

Jeonbuk National University

Emmanuel Afranie

Chungnam National University

Sunny Lee

Jeonbuk National University

Do Hwan Kim

Jeonbuk National University

Chan Hee Park

chonbuk national university

Cheol Sang Kim

Chonbuk National University

Article

Keywords:

Posted Date: February 5th, 2021

DOI: https://doi.org/10.21203/rs.3.rs-199656/v1

License: (c) (1) This work is licensed under a Creative Commons Attribution 4.0 International License.

Read Full License 


\title{
Extraction of non-noble metal columbite-tantalite as a highly efficient electrocatalyst for water splitting
}

\author{
Patrick M. Bacirhonde ${ }^{1,3,4}$, Nelson Y. Dzade ${ }^{2 *}$, Carmen Chalony ${ }^{1,3}$, Jeesoo Park ${ }^{1,3}$, Emmanuel O. \\ Afranie $^{5}$, Sunny Lee ${ }^{1,3}$, Do-Hwan Kim ${ }^{7,8^{*}}$, Chan Hee Park ${ }^{3,6^{*}}$, Cheol Sang Kim ${ }^{3,6^{*}}$ \\ 1 Department of Bionanosystem Engineering, Jeonbuk National University, Jeonju, Jeonbuk 561-756, Republic of \\ Korea
}

2 Energy Materials Semiconductors Surface \& Interface Science Catalysis Materials Modelling \& Simulations, School of Chemistry, Cardiff University, Main Building, Park Place, Cardiff, CF10 3AT, Wales, UK

3 Department of Bionanotechnology and Bioconvergence Engineering, Graduate School, Jeonbuk National University, Jeonju, Republic of Korea

4 Department of Geology and Mining Exploration, University of Goma, 204 Goma, Dem. Rep. Of Congo

5 Department of Materials Science and Engineering, Chungnam National University, 99 Daehang-no, Yuseong-gu, Daejeon, 305-764 Republic of Korea

6 Division of Mechanical Design Engineering, Jeonbuk National University, Jeonju, Jeonbuk 561-756, Republic of Korea

7 Division of Science Education and Institute of Fusion Science, Jeonbuk National University Jeonju, Jeonbuk, 54896 Republic of Korea

8 Department of Energy Storage/Conversion Engineering of Graduate School, Jeonbuk National University, Jeonju, Jeollabuk-do 54896, Republic of Korea

*Corresponding authors: Tel: +82 63270 4284, Fax: +82 632702460

E-mail address: chskim@jbnu.ac.kr (Prof. Cheol Sang Kim)

biochan@jbnu.ac.kr (Prof. Chan Hee Park)

dhk201@jbnu.ac.kr (Prof. Do Hwan Kim)

dzadeny@cardiff.ac.uk (Dr Nelson Y. Dzade) 


\begin{abstract}
The development of robust and inexpensive electrocatalysts that are capable of catalyzing the overall water splitting reaction is highly essential for large scale production of hydrogen. Herein, we report the successful liquid-liquid extraction and hydrothermal synthesis of a highly stable columbite-tantalite electrocatalysts $\left(\mathrm{Fe}_{0.79} \mathrm{Mn}_{0.21} \mathrm{Nb}_{0.16} \mathrm{Ta}_{0.84} \mathrm{O}_{6}\right)$ with remarkable HER and OER performance in alkaline media. The extracted $\mathrm{Fe}_{0.79} \mathrm{Mn}_{0.21} \mathrm{Nb}_{0.16} \mathrm{Ta}_{0.84} \mathrm{O}_{6}$ electrocatalyst shows a low overpotential of 190.2 and $284.8 \mathrm{mV}$ at $10 / \mathrm{mA} \mathrm{cm}^{-2}$ in current density in situ for HER and OER, respectively. The electrocatalyst also exhibited low Tafel slopes of $56.36 \mathrm{mV} / \mathrm{dec}$ for HER and $112.85 \mathrm{mV} / \mathrm{dec}$ for OER, verifying their rapid catalytic kinetics. The electrolyzer maintained the cell voltage of $1.63 \mathrm{~V}$ and potential-time stability close to that of $\mathrm{Pt} / \mathrm{C} \& \mathrm{RuO}_{2} / \mathrm{C}$. The intrinsic mechanism for the exceptional HER and OER performance was further unravelled through firstprinciples density functional theory (DFT) calculations, predicting very low Gibbs free energy of hydrogen adsorption $\left(\Delta \mathrm{GH}^{*} \approx 0.09 \mathrm{eV}\right)$ and low overpotential $(\eta=0.47 \mathrm{eV}$ at the Mn sites) for OER on the $\mathrm{Fe}_{0.75} \mathrm{Mn}_{0.25} \mathrm{Ta}_{1.875} \mathrm{Nb}_{0.125} \mathrm{O}_{6}$ catalyst. Our results demonstrate that columbite-tantalite electrocatalysts offer great promise for efficient overall water splitting.
\end{abstract}




\section{Graphical abstract}
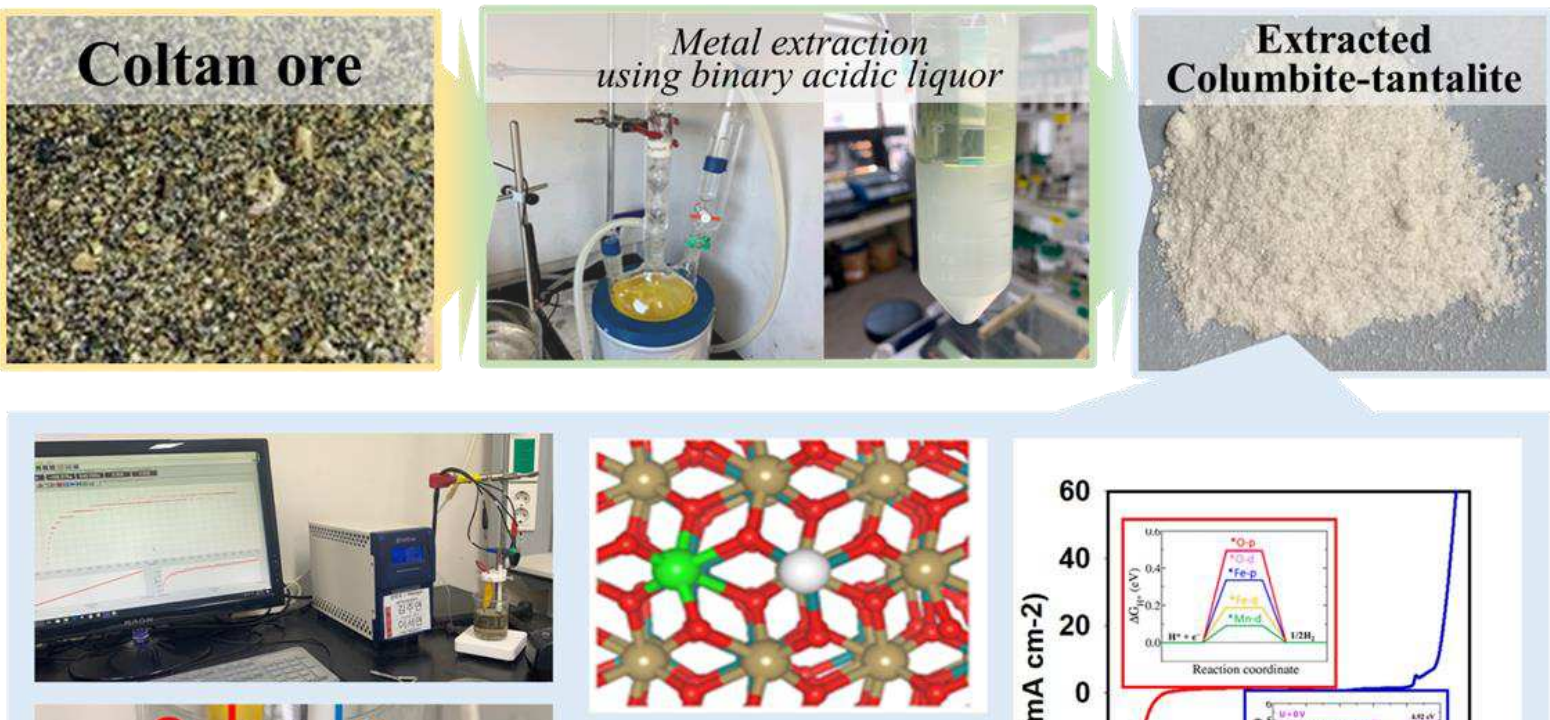

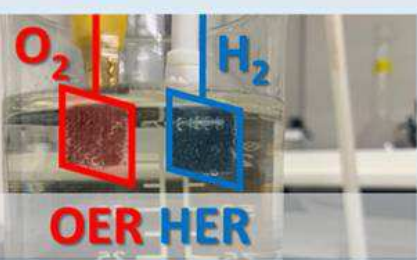

Experiment in-situ

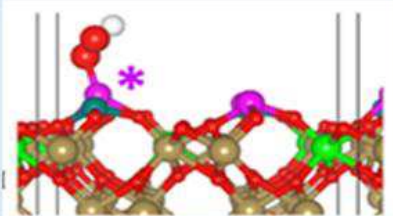

Adsorption structures

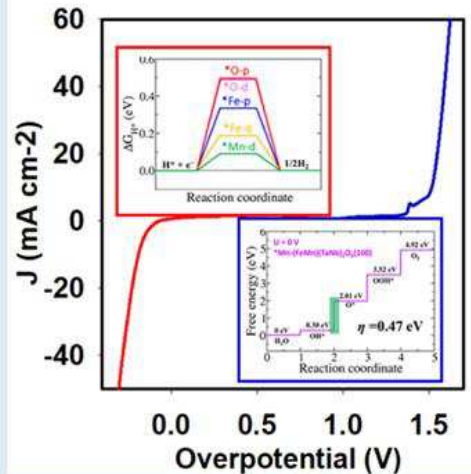

Overall water-splitting 


\section{Introduction}

The rising concerns regarding the depletion of carbon-rich fossil fuels and the increase of environmental pollution necessitates the development of renewable and clean energy technologies. Water splitting to obtain hydrogen and oxygen has been considered as one of the most promising approaches to store renewable electricity in the form of hydrogen fuel ${ }^{1,2}$. Photoelectrochemical water splitting consists of two half reactions: hydrogen evolution reaction (HER) and oxygen evolution reaction (OER). Electrochemical hydrogen production from water electrolysis is however, impeded by the sluggish OER kinetics, which requires high overpotential ${ }^{3}$.

Noble metals (e.g., Pt, Rh, and Ir) and noble metal oxides (e.g., $\mathrm{IrO}_{2}, \mathrm{RuO}_{2}$ ) have receive significant attention as the state-of-the-art electrocatalysts owing to their highly active geometry, long term stability, high current density, and the ability to provide low overpotential to forward HER and OER processes ${ }^{4}$. Nevertheless, the high cost of these catalyst materials limits their widespread practical application ${ }^{5}$. The past decades have therefore, seen a lot of constructive efforts in the development of earth-abundant transition metal-based electrocatalysts for water splitting, such as metal oxides, ${ }^{6,7}$ metal hydroxides, ${ }^{7-9}$ metal chalcogenides, ${ }^{10}$ and metal phosphides, ${ }^{11,12}$ Nevertheless, the facile oxidation and corrosion of transition metal based catalysts limits their use as HER and OER electrocatalysts. ${ }^{13,14}$ Therefore, the rational design and development of transition metal-based electrocatalysts with superior stability and remarkable overall water splitting activity is still in high demand to improve the overall efficiency of water splitting.

Multimetal oxide catalysts have been reported as attractive photo-electrocatalysts in water oxidation/reduction ${ }^{15-17}$. The use of multimetal instead of single-metal oxide catalysts is shown to result in improvements in catalyst stability and performance due to the synergistic effects from the different metal components that tailor/modify the intrinsic properties affecting the HER and OER activity. For example, the incorporation of $\mathrm{Ni}$ into $\mathrm{Co}_{3} \mathrm{O}_{4}$ to form $\mathrm{NiCo}_{2} \mathrm{O}_{4}$ nanosheet array is demonstrated to enhanced the OER activity, which was attributed to increase of the number of active sites ${ }^{18-20}$. Besides that the $\mathrm{NiCO}_{2} \mathrm{O}_{4}$ nanosheet produces a small cell voltage of $1.59 \mathrm{~V}$ to drive a current density of $10 \mathrm{~mA} \mathrm{~cm}^{-2}$ compared to for $\mathrm{Co}_{3} \mathrm{O}_{4}$ catalyst ${ }^{21-23}$. Therefore, it is crucial 
to engineer different types of metal-ligand coordination to create abundant active sites for the electrocatalysis based on the lattice structure ${ }^{24-28}$. Herein, we report for the successful liquid-liquid extraction and hydrothermal synthesis of low-cost columbo-tantalite [i.e., $\mathrm{Fe}_{0.79} \mathrm{Mnn}_{0.21} \mathrm{Nb}_{0.16} \mathrm{Ta}_{0.84} \mathrm{O}_{6}$ ], which exhibits low overpotential and superior stability toward HER and $\mathrm{OER}$ in alkaline media. The $\mathrm{Fe}_{0.79} \mathrm{Mn}_{0.21} \mathrm{Nb}_{0.16} \mathrm{Ta}_{0.84} \mathrm{O}_{6}$ electrocatalyst exhibits low overpotential of 190.2 and $284.8 \mathrm{mV}$ at $10 / \mathrm{mA} \mathrm{cm}^{-2}$ in current density in situ for HER and OER, respectively. Complementary DFT+ $\mathrm{U}$ calculations confirm that the incorporation of $\mathrm{Mn}$ and $\mathrm{Nb}$ in $\mathrm{FeTa}_{2} \mathrm{O}_{6}$ to form $\mathrm{Fe}_{0.75} \mathrm{Mn}_{0.25} \mathrm{Ta}_{1.875} \mathrm{Nb}_{0.125} \mathrm{O}_{6}$ modifies the electronic structure and promote efficient water splitting. Overall, this work demonstrates a real potential for the rational design of columbo-tantalite based electrocatalyst with high electrocatalytic activity and stability for water electrolysis. 


\section{Results}

\section{Mineral extraction and structural analyses}

The coltan (CT) ore was mined in the Democratic Republic of Congo, supplied by the Bisunzu Mining Company (SMB), and hosted by the pegmatite body in the Kibaran Belt. Before any treatment, the CT ore was analyzed by the X-ray fluorescence (XRF) to investigate the chemical compositions, which indicated the presence of $\mathrm{Ta}_{2} \mathrm{O}_{5}(37.7 \%), \mathrm{Nb}_{2} \mathrm{O}_{5}(5.80 \%), \mathrm{Fe}_{2} \mathrm{O}_{3}(8.44 \%)$, $\mathrm{MnO}(0.56 \%), \mathrm{SnO}_{2}$ (7.44\%), $\mathrm{SiO}_{2}$ (15.7\%), $\mathrm{Al}_{2} \mathrm{O}_{3}$ (6.71\%), $\mathrm{TiO}_{2}(3.21 \%), \mathrm{HfO}_{2}(0.14 \%), \mathrm{Rb}_{2} \mathrm{O}$ $(0.27 \%), \mathrm{U}_{3} \mathrm{O}_{8}(0.68 \%)$, and other excluded impurities as shown in Supplementary Table 1. The extraction of white oxyhydroxide coltan filtrated from the CT ore was achieved by the binary $\mathrm{HF} / \mathrm{HCl}$ liquor extraction for an hour at $80^{\circ} \mathrm{C}$ with undiluted methyl isobutyl ketone (MIBK). After the dissolution of CT and extraction of white oxyhydroxide using the well-known organic extractants, MIBK and ammonium solution, their metal contents were ascertained as shown in Fig. 1. The CT sample Fig. 1a is composed of $76.95 \% \mathrm{Ta}, 13 \% \mathrm{Nb}, 4.28 \% \mathrm{Fe}$, and $5.51 \% \mathrm{Mn}$. Conversely, in the reduced phase (WOCT), the elemental concentration was estimated at $87.61 \%$ for $\mathrm{Ta}, 11.28 \%$ for $\mathrm{Nb}, 0.49 \%$ for Fe, and $0.62 \%$ for Mn Fig. 1b using ICP-MS characterisation 29,30. Considering that the extraction process may introduce soluble fluoride compounds impurities, the digested was further purified at $135^{\circ} \mathrm{C}$ (WOCT-135) for 48 hours and calcinated at $1050^{\circ} \mathrm{C}$ (WOCT-1050) for 3 hours, watched with DW and ethanol to obtain columbite tantalite $\left(\mathrm{Fe}_{0.79} \mathrm{Mn}_{0.21} \mathrm{Nb}_{0.16} \mathrm{Ta}_{0.84} \mathrm{O}_{6}\right)$ named WOCT ${ }^{31-34}$.

a

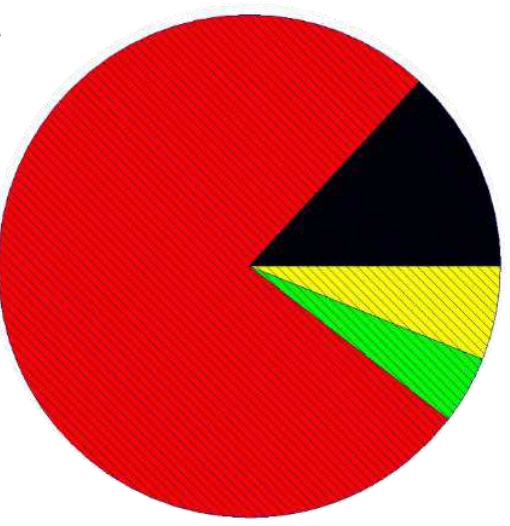

b

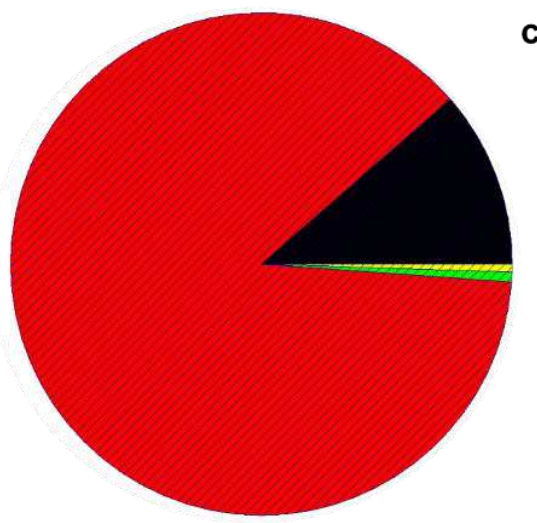

C

\begin{tabular}{lcc}
\hline Elements & \multicolumn{2}{c}{ Contents (\%) } \\
\hline & CT & WOCT \\
Nb & 13.25 & 11.23 \\
Ta & 76.96 & 87.61 \\
Mn & 5.51 & 0.62 \\
Fe & 4.28 & 0.49 \\
\hline Fen & & \\
\hline
\end{tabular}

Fig. 1| Compositional analysis. Pie chart of niobium, tantalum, manganese and iron contents in (a) CT, (b) WOCT and (c) table of correspondent percentage (amount: $0.02 \mathrm{~g}$, volume: $50 \mathrm{~mL}$, and dilution factor: 100 times). 
The crystalline structure of the raw (CT) and extracted (WOCT) were revealed by the X-ray diffraction (XRD) as shown in (Fig. 2a In the case of CT, the corresponding peaks were identified with reference codes: $\mathrm{Ta}_{2} \mathrm{O}_{5}$ (00-054-0514), $\mathrm{Nb}_{2} \mathrm{O}_{5}$ (00-030-0873), $\mathrm{MnO}$ (98.024-7034), and $\mathrm{Fe}_{2} \mathrm{O}_{3}$ (98-015-1723). The crystalline phase in WOCT was $\mathrm{Ta}_{2} \mathrm{O}_{5}(00-035-1193), \mathrm{Nb}_{2} \mathrm{O}_{5}(00-032-$ 0710), $\mathrm{MnO}$ (01-072-1533), and $\mathrm{Fe}_{2} \mathrm{O}_{3}$ (98-009-6076). The peak positions of the various oxides forms are proivided in Supplemetary Table 2 and 3. The WOCT crystallises in the orthorhombic structure (space group: Pbcn) and the lattice parameters $\mathrm{a}=14.3100 \AA, \mathrm{b}=5.7413 \AA$, and $\mathrm{c}=$ $5.0624 \AA$ (Fig. 2b) were determined using Scherrer formula $\left.\left(\frac{1}{d^{2}}=\left(h^{2}+k^{2}\right) \frac{1}{a^{2}}+\frac{l^{2}}{c^{2}}\right)\right)$ with (hkl) as Miller indices ${ }^{35,36}$. Additionally, the strongest reflection peaks appeared at $18.2^{\circ}(110), 23.1^{\circ}$

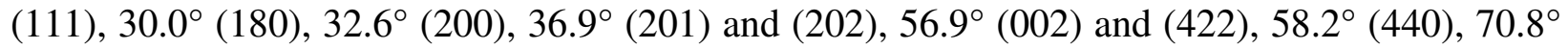
(531), and $77.8^{\circ}(321)$ and (128) of diffraction plane of WOCT crystals forms ${ }^{37}$. 

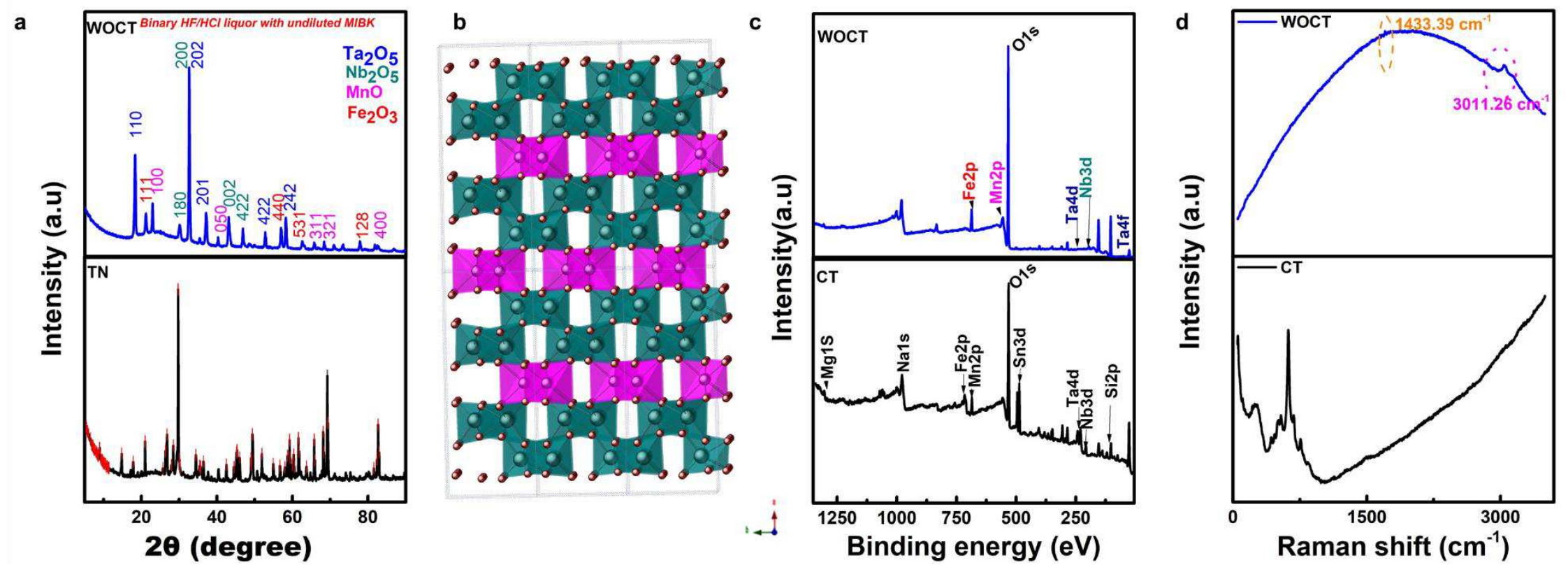

Fig. 2| Structure characterization. (a) XRD pattern, (b) typical $\mathrm{AB}_{2} \mathrm{O}_{6}$ columbo-tantalite structure, $\mathrm{A}$ and $\mathrm{B}$ elements transition metal $(\mathrm{A}=\mathrm{Fe}, \mathrm{Mn}$ and with $\mathrm{B}=\mathrm{Ta}, \mathrm{Nb})$ in Pbcn group octahedrally coordinated to the oxygen atoms), (c) XPS survey, and (d) Raman spectra of the CT and WOCT samples. 
The X-ray photoelectron spectroscopy (XPS) was used to find more information about the electron valence states of the WOCT. All the chemical elements were verified in the XPS spectra of the WOCT (Fig. 2c). Fig. 3(a-f) show the fitted spectra and the corresponding binding energy peaks, where the $\mathrm{Fe}_{2 p}$ localized at 738.77 to $700.08 \mathrm{eV}$ can be assigned to $\mathrm{Fe}^{3+}$ present in $\mathrm{Fe}_{2} \mathrm{O}_{3}, \mathrm{Mn}_{2 p}$ at 659.67 to $632.08 \mathrm{eV}$ indicates $\mathrm{Mn}^{2+}$ in $\mathrm{MnO}, \mathrm{Nb}_{3 \mathrm{~d}}$ at 216.08 to $196.08 \mathrm{eV}$ corresponds to $\mathrm{Nb}^{+5}$ valence in the $\mathrm{Nb}_{2} \mathrm{O}_{5}$, Ta4d at 258.08 to $221.08 \mathrm{eV}$ represents $\mathrm{Ta}^{5+}$ species in the $\mathrm{Ta}_{2} \mathrm{O}_{5}$, and $\mathrm{O}_{1 \mathrm{~s}}$ located at 540.08 to $525.08 \mathrm{eV}$ is attributed to the Metal-OH and the oxygen vacancy. Furthermore, Ta in WOCT shows two different spectra: Ta4d located at $230.81 \mathrm{eV}$ (Fig. 3a) and Ta4f from 40.08 $\mathrm{eV}$ to $20.08 \mathrm{eV}$ (Fig. 3b) indicate that Ta atoms in WOCT exist in the form of $\mathrm{Ta}^{4+}$ 38,39. Raman spectroscopy was also used to compare the raw (CT) and extracted (WOCT) materials (Fig. 2d). The CT peak at $618.2 \mathrm{~cm}^{-1}$ disappeared in the Raman spectra of WOCT. However, a new weak peak was observed at $1433.23 \mathrm{~cm}^{-1}$ and a strong and sharp Raman bond in the high wavenumber range of $3011.26 \mathrm{~cm}^{-1}$ was detected, which corresponds to the out-of-plane of $\mathrm{Ag}$ vibrational mode in WOCT due to the stretching modes of the $\mathrm{Nb}-\mathrm{O}$ and $\mathrm{Ta}-\mathrm{O}$ bonds. The $1433.23 \mathrm{~cm}^{-1}$ sharp peak corresponds to the antisymmetric stretching mode of $\mathrm{Fe}-\mathrm{Ta}$ and $\mathrm{Mn}-\mathrm{Nb}$ bonds ${ }^{40,41}$.
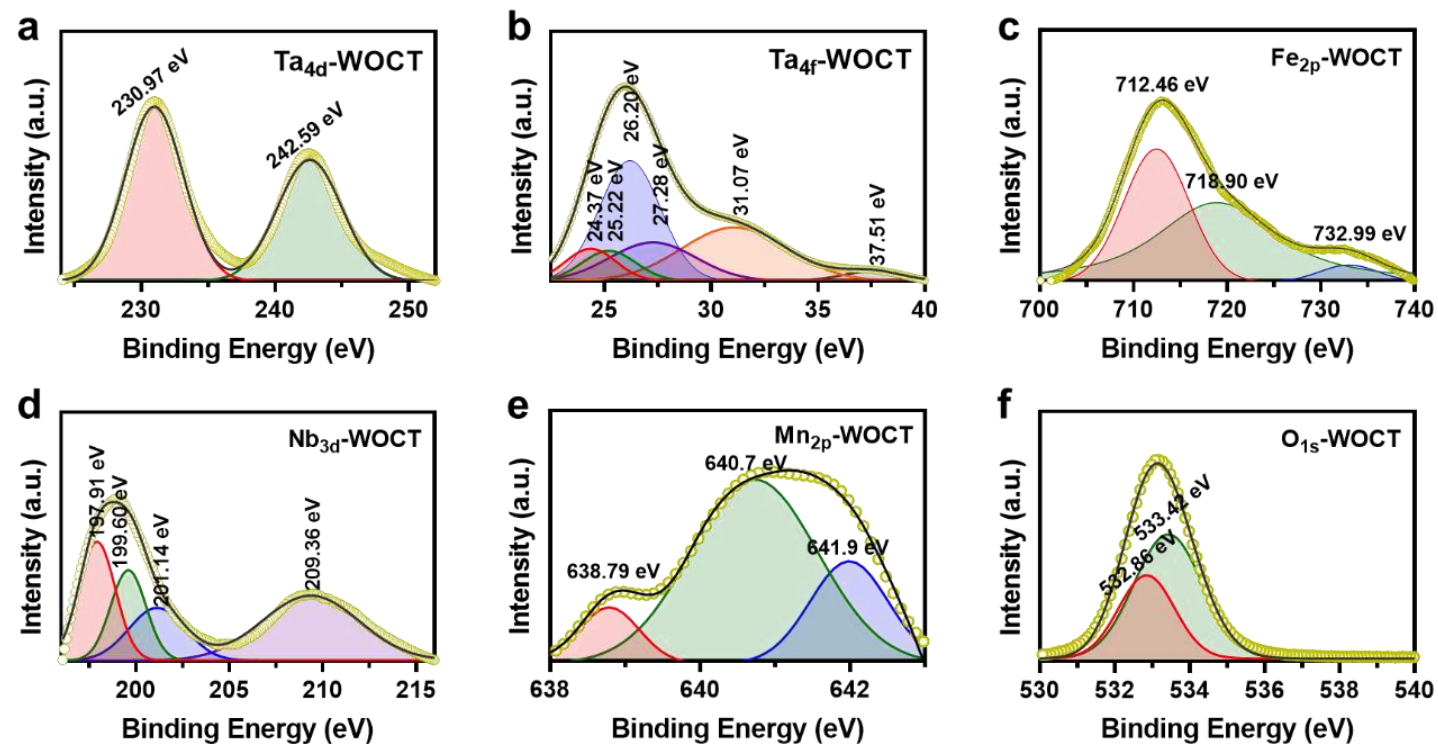

Fig. 3| Chemical structure analysis of catalysts. (a-f): X-ray photoelectron spectroscopy (XPS) of WOCT of the Ta4d, Ta4f, $\mathrm{Fe}_{2 \mathrm{p}}, \mathrm{Nb}_{3 \mathrm{~d}}, \mathrm{Mn}_{2 \mathrm{p}}$, and $\mathrm{O}_{1 \mathrm{~s}}$, peaks. Fitted curves are shown in black and normalized curves are in pea green. Peak intensities are shown for clarification. 
The surface morphology of the coltan ore (Supplementary Fig 1) and extracted WOCT shows that the material exhibits irregular shapes that are tightly stacked in layers with definite edges and basal planes (Fig. 4a-d). Supplementary Figure 2 shows the morphology of all the extracted (WOCT, WOCT-135, WOCT-1050) and synthesized (WOCTs) materials. The energy-dispersive X-ray spectroscopy (EDS) analysis of WOCT confirms that the elements ( $\mathrm{Nb}, \mathrm{Ta}, \mathrm{Fe}, \mathrm{Mn}$, and O) were evenly distributed and homogenized after the extraction (Fig. 4(e and f)) and Supplementary Fig 3 shown the element mapping and Energy dispersive x-ray spectroscopy (EDS) analysis of WOCTs.

a

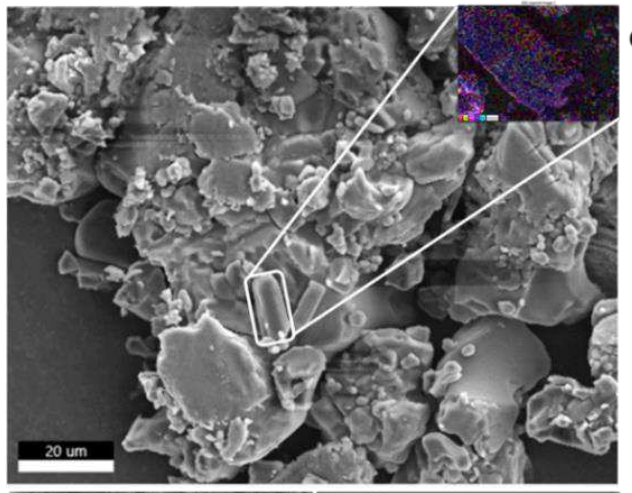

b

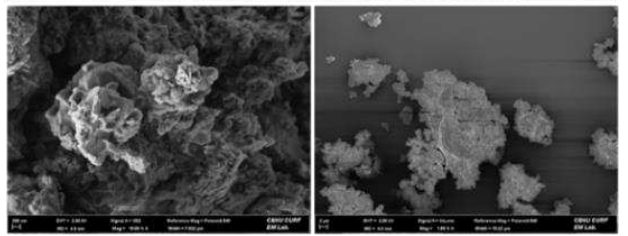

c

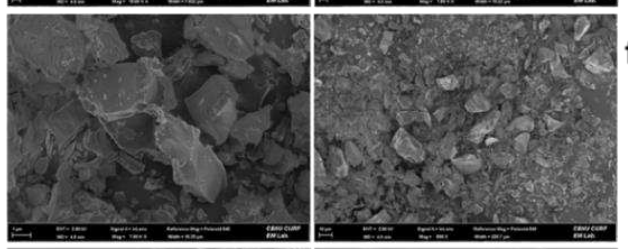

d

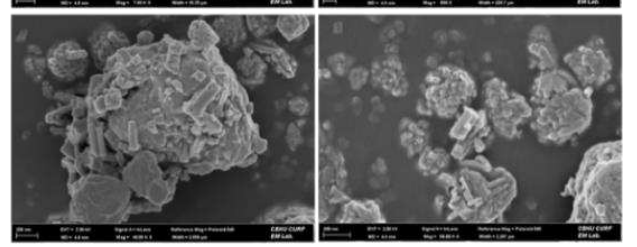

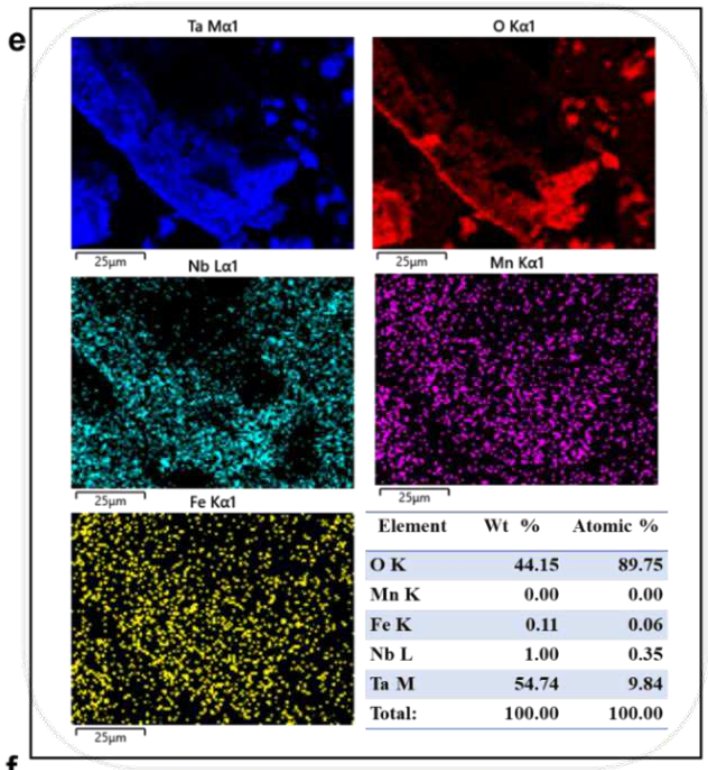

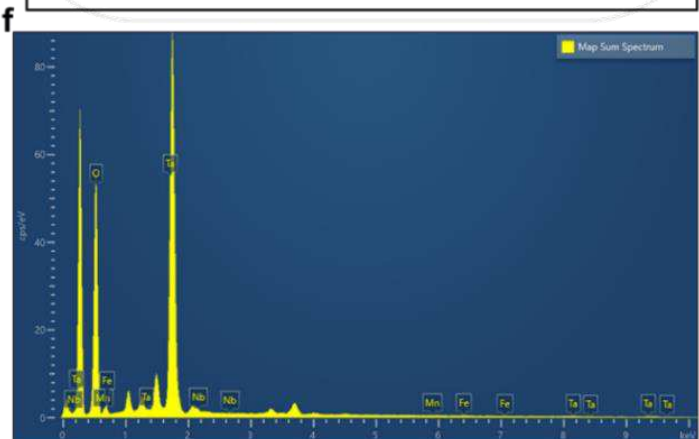

Fig. 4| Morphology and elemental mapping characterization of catalysts. (a-d) External morphology of WOCT, WOCT-135, WOCT-1050 and WOCTs. (e) WOCT FESEM image with elements mapping (O, Nb, Mn, Fe, and Ta). (f) Energy dispersive x-ray spectroscopy (EDS) analysis of WOCT. 
The microstructural characterization of the WOCT were analyzed by TEM (Fig. 5a). The highangle annular dark-field scanning transmission electron microscopy (HAADF-STEM) images (Fig. 5b) confirm the presence of overlaid $\mathrm{Mn}, \mathrm{Fe}, \mathrm{Ta}$, and $\mathrm{Nb}$ atoms. The HRTEM image (Fig. 5d and Supplementary Fig. 4) showsthree different perpendicular directions at an interface (heterostructure) by $0.19 \mathrm{~nm}(022), 0.307 \mathrm{~nm}(210)$, and $0.36 \mathrm{~nm}(211)^{42,43}$. Also, the selected area electron diffraction pattern (Fig. 5e) can be interpreted by the overlapping of the (020), (211), and (210) reciprocal lattice projections ${ }^{44}$. In the analysis of nitrogen adsorption-desorption isotherm (Fig. 5 c), which exhibited the porous structure, the BET surface area, pore-volume, and pore size were calculated at $42.8963 \mathrm{~m}^{2} \mathrm{~g}^{-1}, 0.147865 \mathrm{~cm}^{3} / \mathrm{g}$, and $137.8810 \AA$, respectively. The pore size corresponds to the progress of crystallization according to TEM observation and electron diffraction patterns as shown in Fig. 5f.
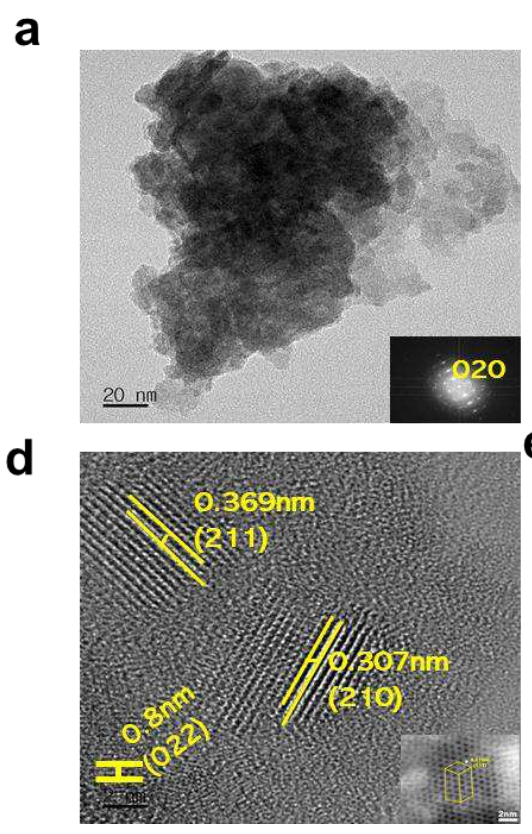

b
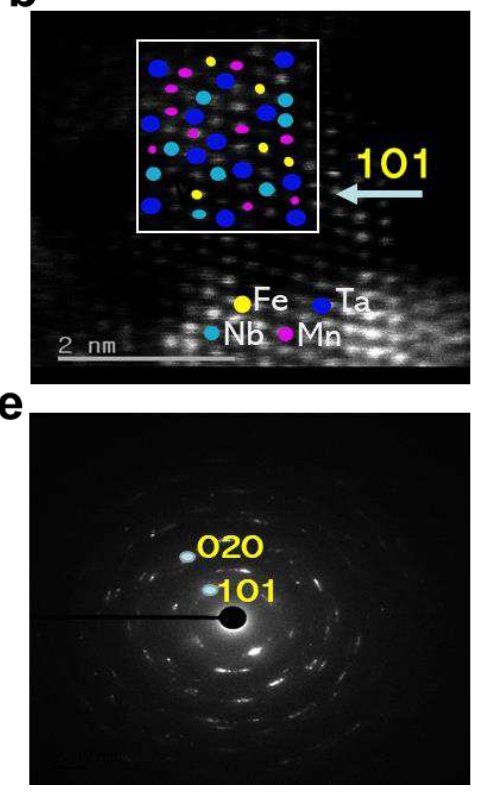

C

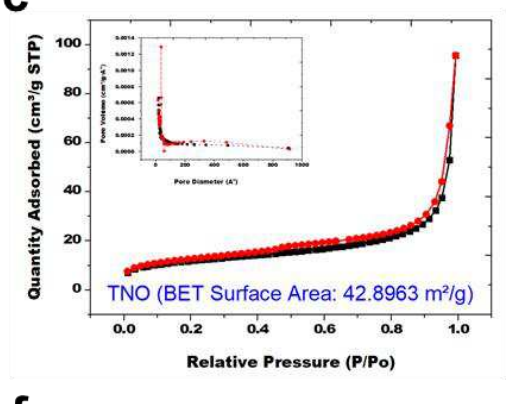

f

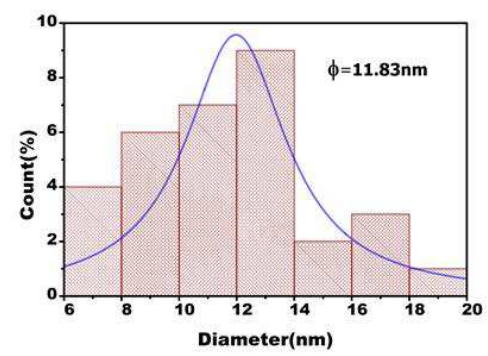

Fig. 5| Microstructural characterization of catalysts. (a) TEM image of WOCT (Inset: diffraction pattern taken under the (020) and (101) zone axis). (b) Selective HAADF-STEM of WOCT taken close to the (101) zone axis with Ta, Nb, Mn, and Fe overlaid atoms. (c) HRTEM image (Inset: a structural model of the threefold superstructure) and (d) the selected area electron diffraction (SAED) of WOCT. (e) Nitrogen adsorption-desorption isotherms (Inset: corresponding 
pore size distributions) of WOCT extracted by the binary acid $\mathrm{HF} / \mathrm{HCl}$ ). (f) Histogram of WOCT particles distribution where the average particle size equals $11.83 \mathrm{~nm}$.

\section{Electrochemical performance}

A three-electrode cell configuration containing $1.0 \mathrm{M}$ potassium hydroxide as an electrolyte was used for the electrochemical measurements of WOCT, Pt/C, WOCT-1050, WOCT-135, synthesised WOCTs, and NF samples. For reference and counter electrodes, the $\mathrm{Hg} / \mathrm{HgO}$ electrode and a graphite rod were used, respectively. Fig. 6(a) shows the HER linear sweep voltammetry (LSV) achieved at a scan rate of $5 \mathrm{mV} \mathrm{s}^{-1}$. Data acquired and by visual evolution of $\mathrm{H}_{2}$ bubbles on the surface of the electrode indicates that the extracted WOCT displays a HER onset voltage of 0.086V Vs RHE and exhibits a low overpotential of $167.9 \mathrm{mV}$ (without IR compensation) at a conventional current density (i) of $10 \mathrm{~mA} \mathrm{~cm}^{-2}$ shown in Supplementary Fig. 5a. Even in allegory to the yardstick platinum electrocatalyst (Pt/C in this case), WOCT exhibits an enhancement of the HER performance under the same reaction conditions. That is to say, $\mathrm{Pt} / \mathrm{C}$ achieved an overpotential of $170.36 \mathrm{mV}$ at $10 \mathrm{~mA} \mathrm{~cm}^{-2}$. On the contrary, the HER overpotential for WOCT $1050(196.61 \mathrm{mV})$, WOCT -135 (196.61 mV), WOCTss $(185.92 \mathrm{mV})$, and NF $(285.11 \mathrm{mV})$ are undoubtedly higher to obtain $10 \mathrm{~mA} \mathrm{~cm}^{-2}$ as shown in Fig. 6(a), confirming the recognizable HER electrocatalytic activity of WOCT. This performance can be attributed to the large surface area that consequently provides more active sites for favorable reactions. The double-layer capacitance $\left(\mathrm{C}_{\mathrm{dl}}\right)$ analysis was investigated to evaluate their electrochemically active surface area (ECSA) as shwown in Supplemetary Fig. 5b. The slope of WOCT (Fig. 6(b)) was recorded as $4.3 \mathrm{mF} \mathrm{cm}^{-2}$ (obtained at 0.97 V, Fig. 6(c)) where no Faradaic charge transfer occurred.

Furthermore, the OER electrocatalytic activities for WOCT, WOCT-135, WOCT-1050, WOCTs, and $\mathrm{RuO}_{2} / \mathrm{C}$ as benchmark reference catalyst, and NF were compared through the polarization curves without IR compensation. Fig. 6(d) shows the recorded linear sweep voltammetry. Both WOCT and $\mathrm{RuO}_{2} / \mathrm{C}$ showed good electrocatalytic properties exhibiting a high limiting current density at a low overpotential for OER. The onset potential of WOCT is $0.278 \mathrm{~V}$ with an overpotential of $284.84 \mathrm{mV}$ at $10 \mathrm{~mA} \mathrm{~cm}{ }^{-2}$. Thes WOCT-135, WOCT-1050, WOCTs, $\mathrm{RuO}_{2} / \mathrm{C}$, and NF samples required $289.1 \mathrm{mV}, 384.31 \mathrm{mV}, 319 \mathrm{mV}, 142.3 \mathrm{mV}$, and $381.87 \mathrm{mV}$ to reach 10 
$\mathrm{mA} \mathrm{cm}^{-2}$, respectively. WOCT shows better performance than WOCT-135, WOCT-1050, WOCTs, and NF electrocatalysts. As WOCT exhibits a higher current density, it implies that the efficiency for $\mathrm{O}_{2}$ production is also higher. The OER turnover frequency (TOF) of WOCT at an overpotential of $284.84 \mathrm{mV}$ is $0.44 /$ sites $\mathrm{s}^{-1}$ (see Supplementary information for calcualtion details). The supplementary Fig 5 (c and d) exhibit the HER and OER performance after IR correction of the WOCT material.

Further insigths into the electrocatalytic activities and their related kinetics for HER were gained from the Tafel plots e shown in Fig. 6(e). The Tafel slope values for WOCT-135, WOCT-1050, WOCTs, WOCT are calcualted at $68.21,67.89,67.48$, and $56.36 \mathrm{mV} \mathrm{dec}^{-1}$, respectively, all of which are close to that of the reference $20 \% \mathrm{Pt} / \mathrm{C}$ electrode $\left(54.61 \mathrm{mV} \mathrm{dec}{ }^{-1}\right)$. The small Tafel slope of $56.36 \mathrm{mV} / \mathrm{dec}$ for WOCT suggest low activation barrier for the Volmer-Tafel or VolmerHeyrovsky steps, therefore resulting in the observed higher HER activity ${ }^{45-48}$. The calculated Tafel plot for OER was 112.85, 174.83, 124.44 , 122.91 , 132.38 , and 127.2 $\mathrm{mV} \mathrm{dec}^{-1}$ for WOCT-135, WOCT-1050, WOCT, WOCTs, NF, and $\mathrm{RuO}_{2} / \mathrm{C}$, respectively (Fig. 6(f)). Compared to the commercial $\mathrm{RuO}_{2} / \mathrm{C}\left(127.2 \mathrm{mV} \mathrm{dec}{ }^{-1}\right)$, WOCT samples gave a small Tafel plot (124.44 mV/dec). When tested for overall water-splitting $\left(\mathrm{H}_{2}\right.$ and $\mathrm{O}_{2}$ bubble formation), WOCT showed excellent performance, reaching $1.63 \mathrm{~V}$ at $10 \mathrm{~mA} \mathrm{~cm}^{-2}$, approaching the $\mathrm{Pt} / \mathrm{C}$ and $\mathrm{RuO}_{2} / \mathrm{C}$ activity (Fig. $6(\mathrm{~g})$ ). Fig. 6(h) shows WOCT displayed strong long-term durability in a potential-time stability test at 20 and $20 \mathrm{~mA} \mathrm{~cm}^{-2}$ constant current density for $32 \mathrm{hr}$. After showing an initial voltage of about $0.54 \mathrm{~V}$ at constant $20 \mathrm{~mA} \mathrm{~cm}{ }^{-2}$ WOCTT appreciated in performance by dropping its voltage to $0.53 \mathrm{~V}$ there about before eventually getting back to $0.54 \mathrm{~V}$ after $24 \mathrm{hr}$ of experiment and then maintaining its stability till the end of the experiment. The test was further stretched to $20 \mathrm{~mA} \mathrm{~cm}^{-}$ 2 for WOCT and Pt/C, like with Pt/C, WOCT showed only superficial form of degradation giving an indication of its high durability.

Furthermore, the structure and morphology of WOCT after electrolysis showed a minimum deformation validated through SEM images (Supplementary Fig. 6) and there was no dissolution of the elemental composition of WOCT . The XRD analysis (Supplementary Fig. 7) also confirmed that the crystal structure of WOCT is maintained after the durability test. Besides, the electrochemical impedance spectroscopy( EIS) test result for the post-water-splitting sample (Fig. 
6(i)) confirmed a charge-transfer capability that was slightly close to the standard one, resulting in the enhanced stability of the WOCT-based device for water splitting in the alkaline media for a long-term operation 

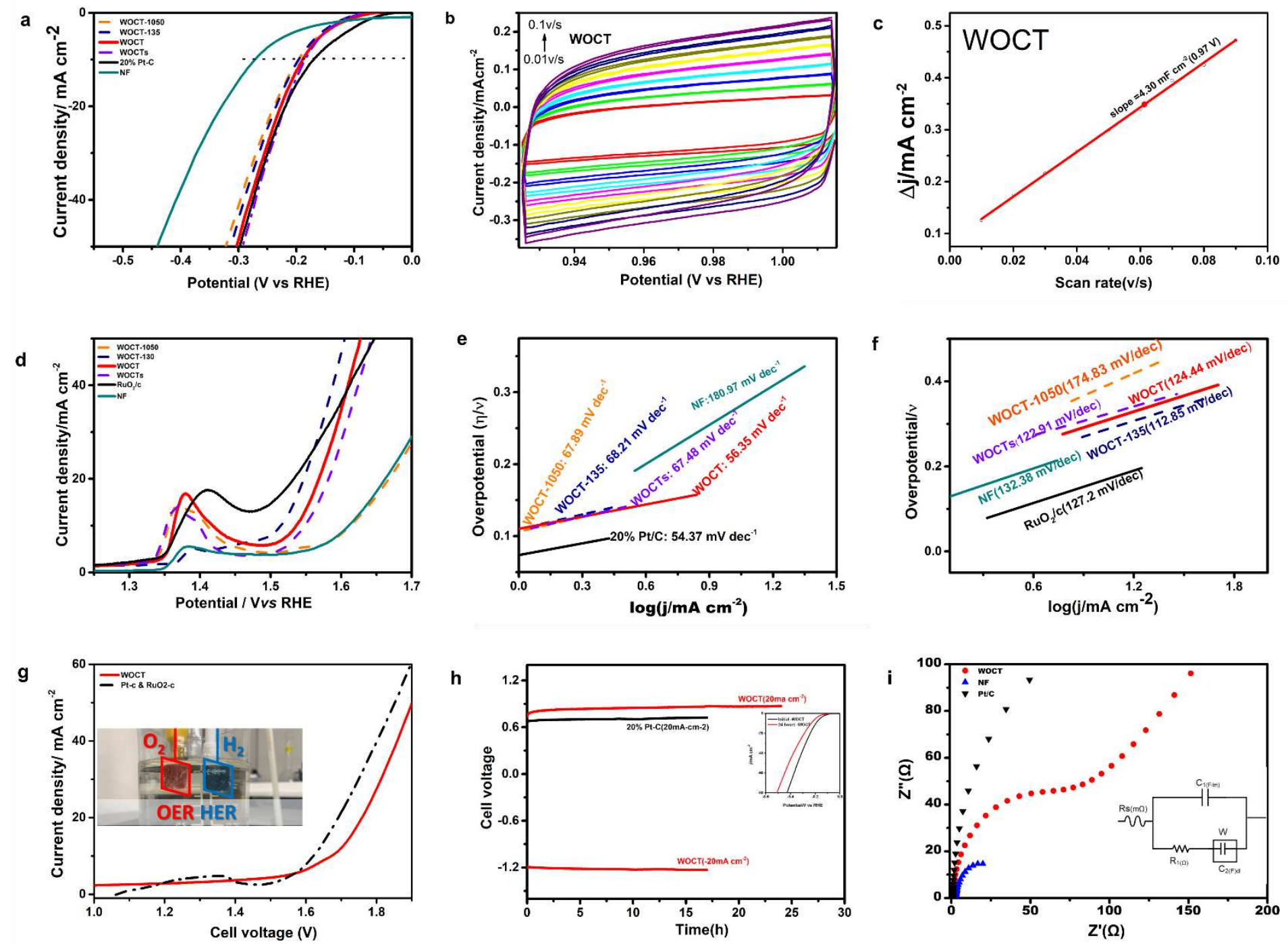
Fig. 6| Fundamental electrochemical relationships measured for HER and OER on catalysts. (a) Linear sweep voltammograms (LSV) curves measured in $1 \mathrm{M} \mathrm{KOH}$ at a scan rate of $5 \mathrm{mV} \mathrm{s}^{-1}$. (b) Cyclic voltammograms. (c) charging current density differences $(\Delta \mathrm{j}=\mathrm{ja}-\mathrm{jc})$ as a function of the scan rate, $\mathrm{C}_{\mathrm{dl}}$ obtained by the $\mathrm{Cv}$ at $0.97 \mathrm{v} \mathrm{Hg} / \mathrm{HgO}$. (d) OER-LSV polarization curves. (e-f) corresponding Tafel plot of HER and OER. (g) LSV comparing the water -splitting performance of WOCT and $\mathrm{Pt} / \mathrm{C} \& \mathrm{RuO}_{2} / \mathrm{C}$ (inset image of electrolyzer step for overall water splitting). (h) Durability test of WOCT and Pt/C evaluated at $\mathrm{j}=-20$ and $20 \mathrm{~mA} \mathrm{~cm}^{-2}$ (inset: HER-LSV shows the initial and after 24 hours). (i) Electrochemical impedance spectroscopy (EIS) of WOCT and $\mathrm{Pt} / \mathrm{C}$ (inset image is an analog circuit diagram).

\section{Density Functional Theory (DFT)}

To gain further insights into the electrochemical performance of $(\mathrm{Fe}, \mathrm{Mn})(\mathrm{Nb}-\mathrm{Ta})_{2} \mathrm{O}_{6}$ catalyst towards HER and OER, first principles Hubbard-corrected density functional theory (DFT+U) calculations was employed to simulate the HER activity and the OER process. The pure FeTa2O6 and the doped phase with composition $\mathrm{Fe}_{0.75} \mathrm{Mn}_{0.25} \mathrm{Ta}_{1.875} \mathrm{Nb}_{0.125} \mathrm{O}_{6}$ were modelled to investigate the effect of $\mathrm{Mn}$ and $\mathrm{Nb}$ doping on the structural, electronic, and electrochemical performance. The optimized bulk structures and their corresponding unit cell parameters are shown in Supplementary Fig. 8. The incorporation of $\mathrm{Mn}$ and $\mathrm{Nb}$ into the lattice is found to resulted in a small expansion of the lattice. The most stable (100) surface (Supplementary Fig. 9) was used to characterize the HER and the OER activity of the $\mathrm{FeTa}_{2} \mathrm{O}_{6}$ and $\mathrm{Fe}_{0.75} \mathrm{Mn}_{0.25} \mathrm{Ta}_{1.875} \mathrm{Nb}_{0.125} \mathrm{O}_{6}$ catalysts. The topmost layer of the $(2 \times 2) \mathrm{FeTa}_{2} \mathrm{O}_{6}(100)$ is composed of four Fe ions whereas the $\mathrm{Fe}_{0.75} \mathrm{Mn}_{0.25} \mathrm{Ta}_{1.875} \mathrm{Nb}_{0.125} \mathrm{O}_{6}(100)$ has two $\mathrm{Fe}$ and $2 \mathrm{Mn}$ ions in the topmost layer.

The HER activity was evaluated by calculating the Gibbs free energy of hydrogen adsorption $\left(\Delta \mathrm{GH}^{*}\right)$ at different possible active sites on the $\mathrm{FeTa}_{2} \mathrm{O}_{6}$ and $\mathrm{Fe}_{0.75} \mathrm{Mn}_{0.25} \mathrm{Ta}_{1.875} \mathrm{Nb}_{0.125} \mathrm{O}_{6}$ (100) surface. The $\Delta \mathrm{G}_{\mathrm{H}}$ is a good descriptor of the electrocatalytic activity of materials toward $\mathrm{HER}^{49-}$ 51. A $\Delta \mathrm{G}_{\mathrm{H}^{*}}$ as close as possible to zero is preferred as it shows that free energy of adsorbed $\mathrm{H}$ is close to that of the reactant or product. Fig. 7 shows the most stable HER intermediate at different binding sited on the pure (p) FeTa $2 \mathrm{O}_{6}$ and doped (d) $\mathrm{Fe}_{0.75} \mathrm{Mn}_{0.25} \mathrm{Ta}_{1.875} \mathrm{Nb}_{0.125} \mathrm{O}_{6}$ surfaces. The free 
energy profile for HER (Fig. 8a) shows that the pure FeTa2 $\mathrm{O}_{6}(100)$ has higher $\Delta \mathrm{G}_{\mathrm{H}^{*}}$ values compared to that of the doped $\mathrm{Fe}_{0.75} \mathrm{Mn}_{0.25} \mathrm{Ta}_{1.875} \mathrm{Nb}_{0.125} \mathrm{O}_{6}$ surface.

The $\Delta \mathrm{GH}^{*}$ for the pure FeTa2 $\mathrm{O}_{6}(100)$ is calculated to be $0.33 \mathrm{eV}$ at the Fe site and $0.50 \mathrm{eV}$ at the $\mathrm{O}$ site on the pure $\mathrm{FeTa}_{2} \mathrm{O}_{6}(100)$. A reduction in the $\Delta \mathrm{G}^{*}$ values is observed at the doped

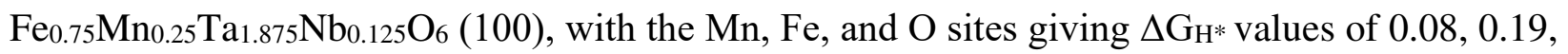
and $0.49 \mathrm{eV}$, respectively. The $\Delta \mathrm{G}_{\mathrm{H}^{*}}$ value at the $\mathrm{Mn}$ site is similar to that of the well-known and highly efficient Pt catalyst $\left(\left|\Delta \mathrm{GPt}_{\mathrm{H}}{ }^{*}\right| \approx 0.09 \mathrm{eV}\right)^{50,52,53}$. The smaller $\Delta \mathrm{G}_{\mathrm{H}^{*}}$ for the $\mathrm{H}-\mathrm{Mn}$ and $\mathrm{H}-\mathrm{Fe}$ interactions at the doped $\mathrm{Fe}_{0.75} \mathrm{Mn}_{0.25} \mathrm{Ta}_{1.875} \mathrm{Nb}_{0.125} \mathrm{O}_{6}$ (100) surface suggest that bonds are not too strong or too weak to limit the recombination of the adsorbed $\mathrm{H}$ atoms to evolve molecular hydrogen via a Volmer-Tafel or Volmer-Heyrovsky mechanism ${ }^{54}$. This results indicate that the doped $\mathrm{Fe} 0.75 \mathrm{Mn}_{0.25} \mathrm{Ta}_{1.875} \mathrm{Nb}_{0.125} \mathrm{O}_{6}$ is a more active HER catalyst than pure FeTa2 $\mathrm{O}_{6}$.
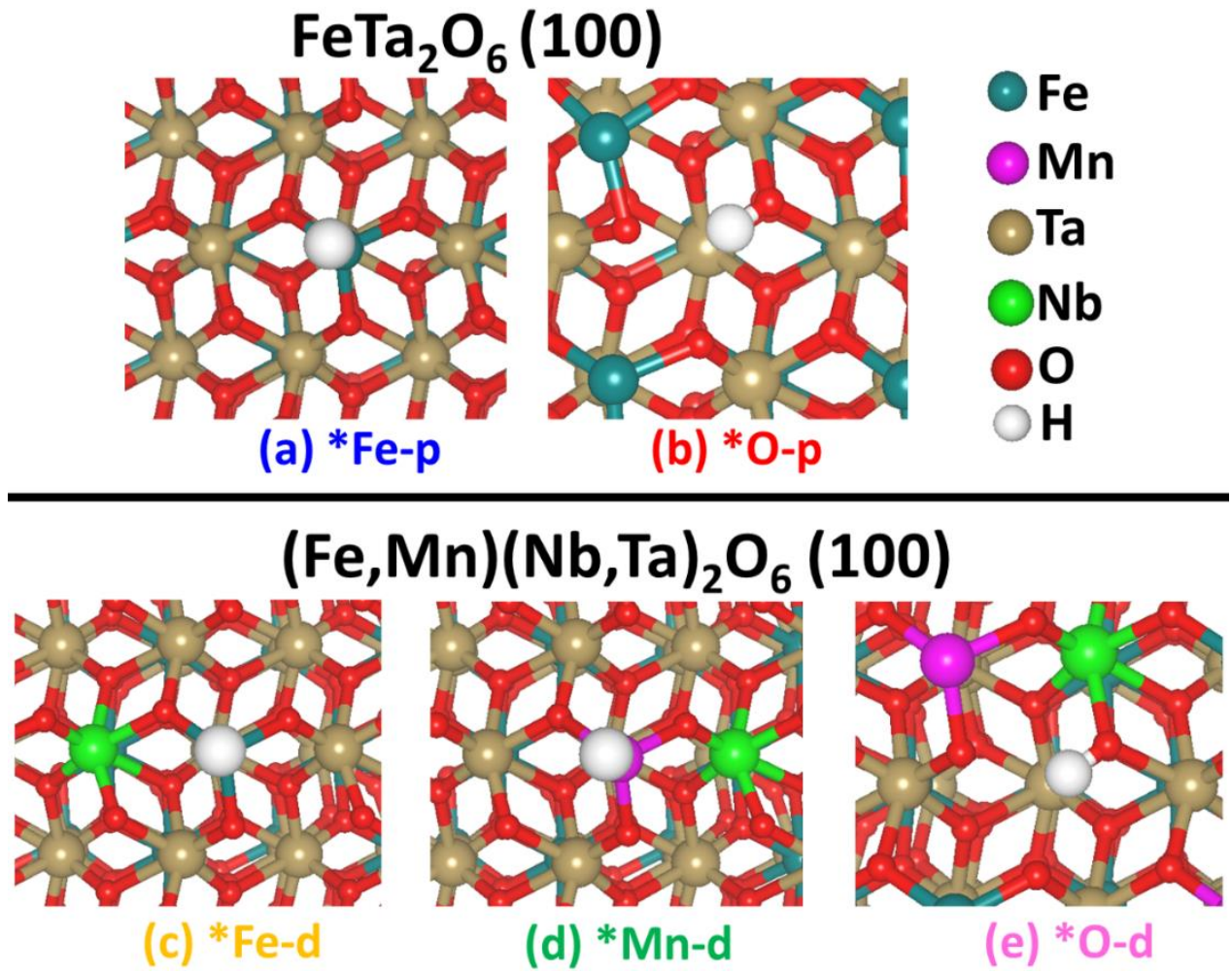

Fig. 7| DFT characterization of $\mathbf{H}$ adsorption structures. Adsorption structures of $H$ (HER intermediate) on pure (a \& b) FeTa2 $\mathrm{O}_{6}$ and on doped (c-e) $\mathrm{Fe}_{0.75} \mathrm{Mn}_{0.25} \mathrm{Ta}_{1.875} \mathrm{Nb}_{0.125} \mathrm{O}_{6}$ (100) surfaces. 
(a)

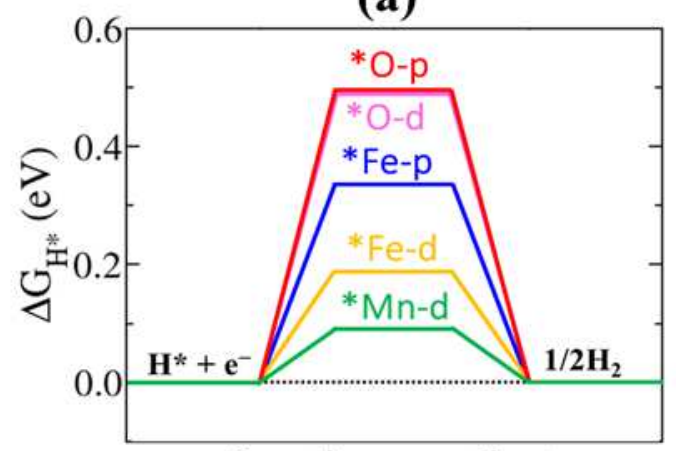

Reaction coordinate

(c)

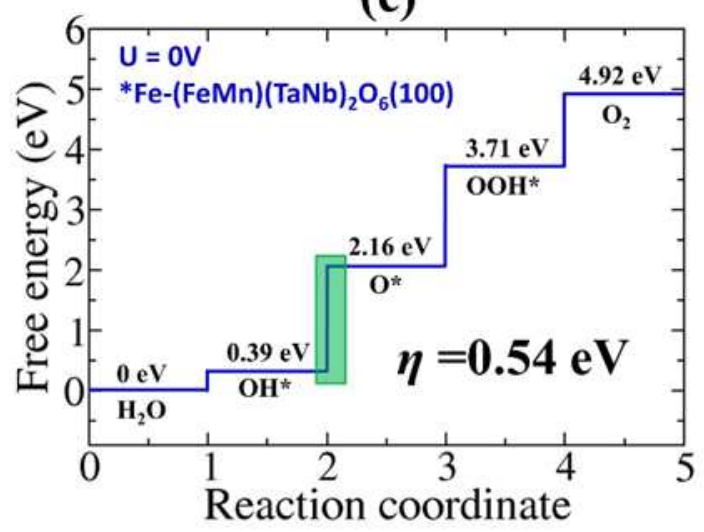

(e)

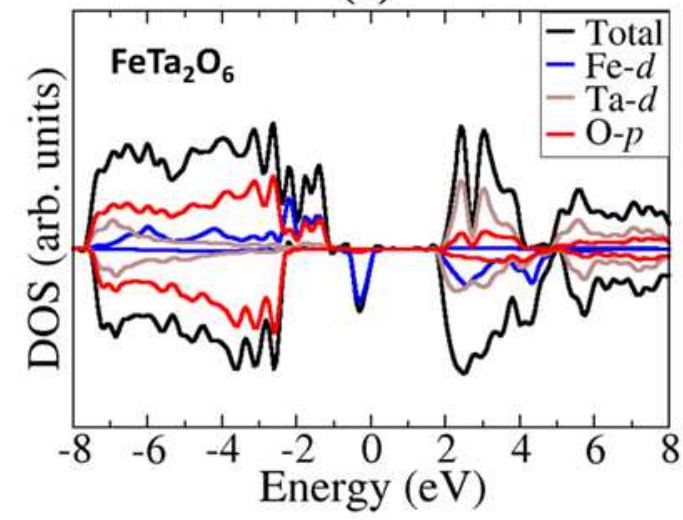

(b)

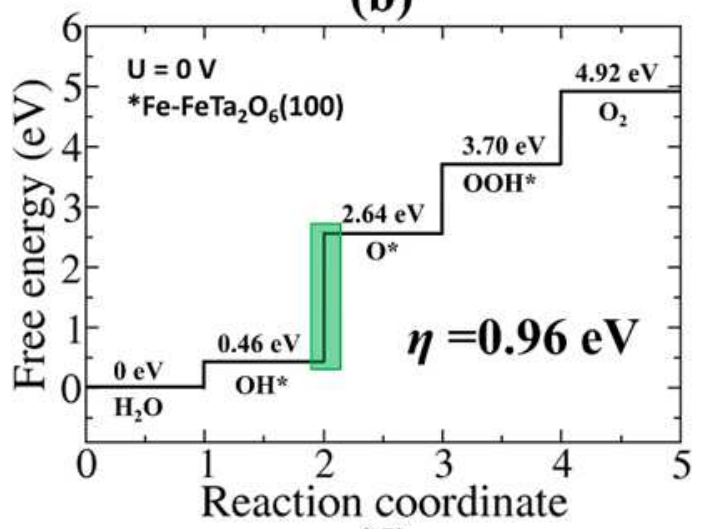

(d)

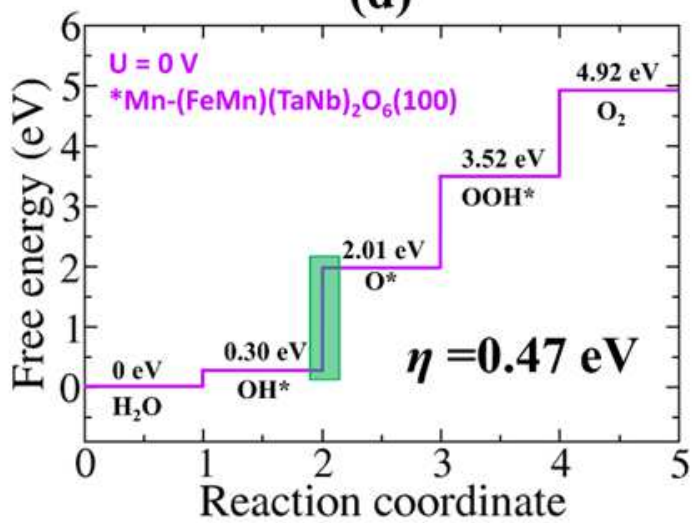

(f)

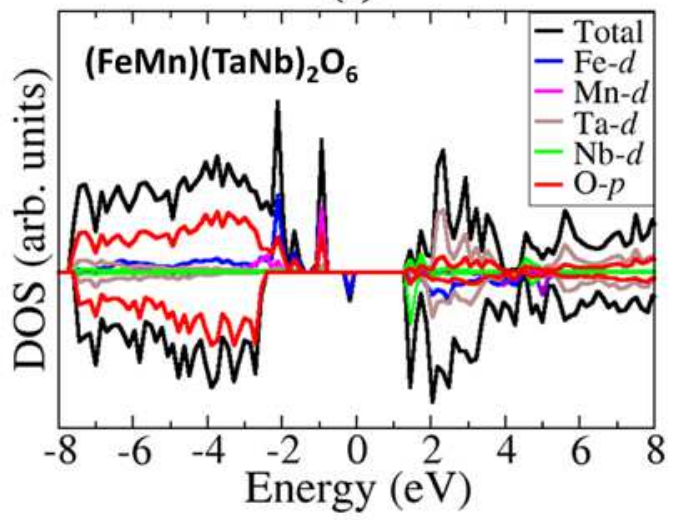

Fig. 8| DFT calculation for the HER and OER mechanism. (a) Gibbs free energy of hydrogen adsorption $\left(\Delta \mathrm{GH}^{*}\right)$ at different possible active sites on pure-p $\mathrm{FeTa}_{2} \mathrm{O}_{6}(100)$ and doped-d $\mathrm{Fe}_{0.75} \mathrm{Mn}_{0.25} \mathrm{Ta}_{1.875} \mathrm{Nb}_{0.125} \mathrm{O}_{6}(100)$. Gibbs free-energy diagram for four steps of OER on (b) Fe site at $\mathrm{FeTa}_{2} \mathrm{O}_{6}(100)$ (c) $\mathrm{Fe}$ site at $\mathrm{Fe}_{0.75} \mathrm{Mn}_{0.25} \mathrm{Ta}_{1.875} \mathrm{Nb}_{0.125} \mathrm{O}_{6}(100)$ and (d) $\mathrm{Mn}$ site on $\mathrm{Fe}_{0.75} \mathrm{Mn}_{0.25} \mathrm{Ta}_{1.875} \mathrm{Nb}_{0.125} \mathrm{O}_{6}(100)$. The marked green box denotes the rate determining step and $\eta$ is the overpotential. (e) and (f) are the elecronic partial density of states (PDOS) for pure $\mathrm{FeTa}_{2} \mathrm{O}_{6}$ and dope $\mathrm{Fe}_{0.75} \mathrm{Mn}_{0.25} \mathrm{Ta}_{1.875} \mathrm{Nb}_{0.125} \mathrm{O}_{6}$ materials. 
The possible reaction steps of the OER have been studied on the pure $\mathrm{FeTa}_{2} \mathrm{O}_{6}$ and doped $\mathrm{Fe}_{0.75} \mathrm{Mn}_{0.25} \mathrm{Ta}_{1.875} \mathrm{Nb}_{0.125} \mathrm{O}_{6}$ (100) surfaces to calculate the Gibbs free energy of coordinate elementary steps and overpotential for OER based on the following 4e-mechanism proposed by Norskov for water oxidation ${ }^{55,56}$ :

$*+\mathrm{H}_{2} \mathrm{O} \rightarrow \mathrm{HO}^{*}+\left(\mathrm{H}^{+}+\mathrm{e}^{-}\right) \quad \Delta \mathrm{G}_{\mathrm{I}}$

$\mathrm{HO}^{*} \rightarrow \mathrm{O}^{*}+\left(\mathrm{H}^{+}+\mathrm{e}^{-}\right) \quad \Delta \mathrm{G}_{\mathrm{II}}$

$\mathrm{O}^{*}+\mathrm{H}_{2} \mathrm{O} \rightarrow \mathrm{HOO}^{*}+\left(\mathrm{H}^{+}+\mathrm{e}^{-}\right) \quad \Delta \mathrm{G}$ III

$\mathrm{HOO}^{*} \rightarrow *+\mathrm{O}_{2}+\left(\mathrm{H}^{+}+\mathrm{e}^{-}\right) \quad \Delta \mathrm{GIV}$

where $*$ stands for the active sites on the surface and $\mathrm{O}^{*}, \mathrm{HO}^{*}$, and $\mathrm{HOO}^{*}$ denote the adsorbed oxygenated species. The $\Delta \mathrm{G}_{\mathrm{I}}, \Delta \mathrm{G}_{\mathrm{II}}, \Delta \mathrm{G}_{\mathrm{III}}$, and $\Delta \mathrm{G}_{\mathrm{IV}}$ represents the reaction Gibbs free energies. The overpotential $\eta$ is determined as $\eta=\max \left(\Delta \mathrm{G}_{\mathrm{I}}, \Delta \mathrm{G}_{\mathrm{II}}, \Delta \mathrm{G}_{\mathrm{III}}, \Delta \mathrm{G}_{\mathrm{IV}}\right)-1.23 \mathrm{eV}$.

The Gibbs free energy profile for the proposed 4e-mechanism of oxygen evolution reaction at the pure FeTa2 $\mathrm{O}_{6}$ and doped $\mathrm{Fe}_{0.75} \mathrm{Mn}_{0.25} \mathrm{Ta}_{1.875} \mathrm{Nb}_{0.125} \mathrm{O}_{6}$ (100) surfaces is presented in Fig. 8 (b-d). The optimized structures of the $* \mathrm{OH}, * \mathrm{O}$, and $* \mathrm{OOH}$ intermediates for the OER are shown in Fig. 9. The rate determining step (i.e. the largest Gibbs free energy difference) is predicted to be StepII for all active sites on the pure $\mathrm{FeTa}_{2} \mathrm{O}_{6}$ and doped $\mathrm{Fe}_{0.75} \mathrm{Mn}_{0.25} \mathrm{Ta}_{1.875} \mathrm{Nb}_{0.125} \mathrm{O}_{6}$ (100) surfaces, as shown in Fig. 9. The Gibbs free energy difference for the Fe-site on the pure $\mathrm{FeTa}_{2} \mathrm{O}_{6}(100)$ surface is predicted at $\Delta \mathrm{G}_{\mathrm{II}}=2.19 \mathrm{eV}$, which is larger than that of the $\mathrm{Fe}\left(\Delta \mathrm{G}_{\mathrm{II}}=1.77 \mathrm{eV}\right)$ and $\mathrm{Mn}$ $(\Delta \mathrm{GII}=1.70 \mathrm{eV})$ sites at the doped $\mathrm{Fe}_{0.75} \mathrm{Mn}_{0.25} \mathrm{Ta}_{1.875} \mathrm{Nb}_{0.125} \mathrm{O}_{6}$ surface. These results indicate the doped $\mathrm{Fe}_{0.75} \mathrm{Mn}_{0.25} \mathrm{Ta}_{1.875} \mathrm{Nb}_{0.125} \mathrm{O}_{6}$ (100) surface requires a lower overpotential $(\eta=0.47 \mathrm{eV}$ at the Mn sites and $\eta=0.54$ at the Fe site) to drive water oxidation than the pure FeTa2 $\mathrm{O}_{6}$ (100) surface $(\eta=0.96 \mathrm{eV})$.

The improved performance of the doped $\mathrm{Fe}_{0.75} \mathrm{Mn}_{0.25} \mathrm{Ta}_{1.875} \mathrm{Nb}_{0.125} \mathrm{O}_{6}$ (100) surface was rationalized by determining the projected density of states of the pure $\mathrm{FeTa}_{2} \mathrm{O}_{6}$ and doped $\mathrm{Fe}_{0.75} \mathrm{Mn}_{0.25} \mathrm{Ta}_{1.875} \mathrm{Nb}_{0.125} \mathrm{O}_{6}$ material are shown in Fig. 8 (e and $\mathrm{f}$ ). The incorporation of $\mathrm{Mn}$ 
introduced states at the valence band edge whereas $\mathrm{Nb}$ introduces states at the conduction band edge. The band gap is also narrowed with $\mathrm{Mn}$ and $\mathrm{Nb}$ incorporation, suggesting improvement in the electric conductivity of the doped material. This is consistent with lower overpotential and therefore improved OER performance predicted for the doped $\mathrm{Fe}_{0.75} \mathrm{Mn}_{0.25} \mathrm{Ta}_{1.875} \mathrm{Nb}_{0.125} \mathrm{O}_{6}$ than the pure $\mathrm{FeTa}_{2} \mathrm{O}_{6}$. 
(a) $*$ Fe- $\mathrm{FeTa}_{2} \mathrm{O}_{6}(\mathbf{1 0 0})$

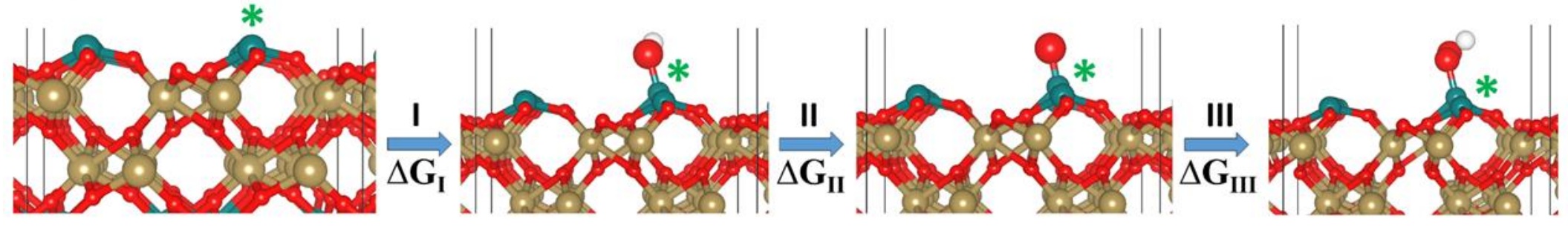

(b) $* \mathrm{Fe}-(\mathrm{FeMn})(\mathrm{TaNb})_{2} \mathrm{O}_{6}(100)$

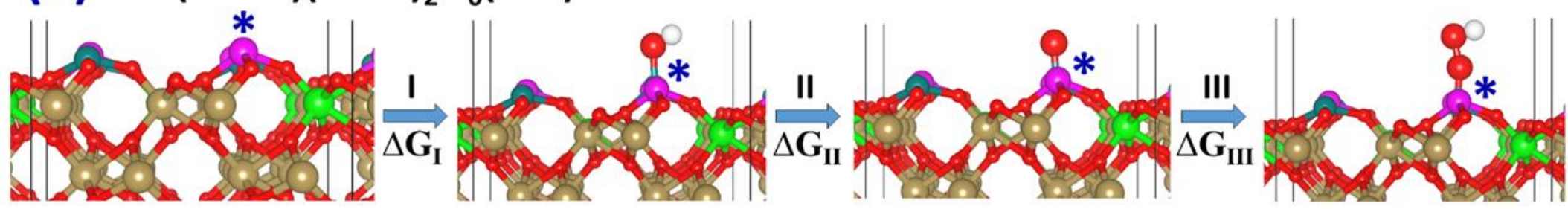

$(\mathrm{c}) * \mathrm{Mn}-(\mathrm{FeMn})(\mathrm{TaNb})_{2} \mathrm{O}_{6}(100)$

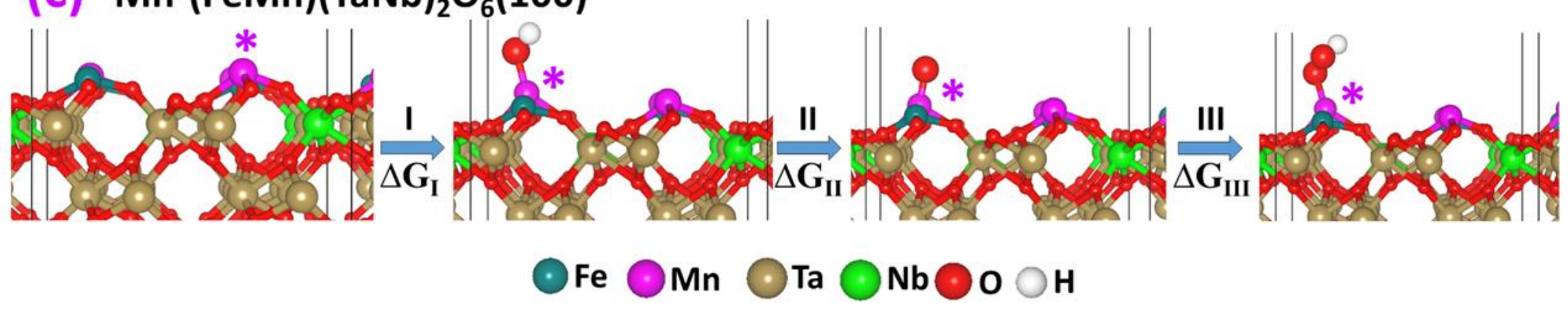

Fig. 9| DFT characterization of OER intermediates. Optimised adsorption structures of OER intermediates $(* \mathrm{OH}, * \mathrm{O}$, and $* \mathrm{OOH})$

at (a) Fe-site on $\mathrm{FeTa}_{2} \mathrm{O}_{6}(100)$, (b) at Fe-site and (c) at Mn-site at doped $\mathrm{Fe}_{0.75} \mathrm{Mn}_{0.25} \mathrm{Ta}_{1.875} \mathrm{Nb}_{0.125} \mathrm{O}_{6}(100)$. 


\section{Discussion}

In summary, we report the successful liquid-liquid extraction and hydrothermal synthesis of columbite-tantalite electrocatalysts $\left(\mathrm{Fe}_{0.79} \mathrm{Mn}_{0.21} \mathrm{Nb}_{0.16} \mathrm{Ta}_{0.84} \mathrm{O}_{6}\right)$ and systematically evaluated for the first time their HER and OER catalytic activities in alkaline conditions. The extracted (WOCT) and synthesized (WOCTs) $\mathrm{Fe}_{0.79} \mathrm{Mn}_{0.21} \mathrm{Nb}_{0.16} \mathrm{Ta}_{0.84} \mathrm{O}_{6}$ electrocatalysts showed excellent electrocatalytic performance, exhibiting low overpotential of $167.9 \mathrm{mV}$ and $185.92 \mathrm{mV}$ for HER and $284.84 \mathrm{mV}$ and $319 \mathrm{mV}$ for OER at $10 \mathrm{~mA} \mathrm{~cm}^{-2}$, respectively, in alkaline media. The extracted $\mathrm{Fe} 0.79 \mathrm{Mn} 0.21 \mathrm{Nb} 0.16 \mathrm{Ta} 0.84 \mathrm{O}_{6}$ also displayed long term durability in a potential-time stability test at 20 and $20 \mathrm{~mA} \mathrm{~cm}^{-2}$ constant current density for $32 \mathrm{hr}$. Besides that the Tafel slope for WOCT and WOCTs are compare closely to those of $\mathrm{Pt} / \mathrm{C}$ or $\mathrm{RuO}_{2} / \mathrm{C}$ commercial catalysts, indicating faster kinetic activity for electron transfer in alkaline media. The experimental results were corroborated by DFT calculations, which demonstrate that $\mathrm{Fe}_{0.75} \mathrm{Mn}_{0.25} \mathrm{Ta}_{1.875} \mathrm{Nb}_{0.125} \mathrm{O}_{6}$ can enhance the adsorption energetics and boost the kinetics of the electrocatalytic water splitting process. This work should open more avenues for the rational design and development of columbite-tantalite based electrocatalysts as promising alternative to the expensive noble metal catalysts for renewable and sustainable energy conversion. 


\section{Methods}

\section{Mineral extraction}

The columbite-tantalite ore (coltan) was crushed and sieved $(<100 \mu \mathrm{m})$ at the beginning and $10 \mathrm{~g}$ was weighed for the digestion process. For leaching of the columbite-tantalite ore samples, twostep binary acid system was employed using the mixture of hydrofluoric (HF) and sulfuric acids $(\mathrm{HCl})$. First, the digestion of the coltan ore was placed in a polypropylene beaker with $8 \mathrm{M} \mathrm{HF}$ and stirred at room temperature for $3 \mathrm{~h}$, followed by adding $8 \mathrm{M} \mathrm{HCL}$ and stirring the mixture at $80^{\circ} \mathrm{C}$ for $8 \mathrm{~h}$. Then, the dissolved metals was filtrated ${ }^{29,33,57}$. Secondly, the liquid-liquid extraction was carried out with $10 \mathrm{~mL}$ of filtrated solution added to $10 \mathrm{~mL}$ methyl isobutyl ketone (MIBK) and maintained at $25^{\circ} \mathrm{C}$ for $15 \mathrm{~min}$ to form the organo-metallic complex ${ }^{58-60}$. The solution was separated using a separation funnel. A $20 \mathrm{~mL}$ of the organo-metallic solution was then transferred back into a $50 \mathrm{~mL}$ conical tube and $25 \%$ ammonia solution of equal volume $\left(\mathrm{V}_{\mathrm{aq}} / \mathrm{V}_{\text {org }}\right)$ was added to allow the metal hydroxides separation. The white precipitate was allowed to settle for $1 \mathrm{~h}$ and then centrifuged at $7000 \mathrm{rpm}$ for $10 \mathrm{~min}$. The formed white wet cake was washed with deionized water, transferred to a glass beaker, and dried in vacuum oven for $48 \mathrm{~h}$ at $135^{\circ} \mathrm{C}$ (WOCT-135) to ensure that all the organic solvents were removed. The dried cakes were placed in a porcelain crucible for calcination at $1050^{\circ} \mathrm{C}$ for $3 \mathrm{~h}$ in a muffle furnace (WOCT-1050) $)^{61,62}$. The annealed grey metal oxide was milled and further used after washing in ethanol and distiller water (WOCT) in this study (photo all the extraction process shown on the Supplementary Fig. 10).

The synthetic columbite-tantalite $\mathrm{AB}_{2} \mathrm{O}_{6}(\mathrm{~A}=\mathrm{Fe}, \mathrm{Mn}$, and $\mathrm{B}=\mathrm{Nb}$, Ta $)$ was prepared by a hydrothermal method, followed by calcination ${ }^{59,60}$. First, $0.2 \mathrm{mmol}$ ammonium niobate(V) oxalate hydrate was dissolved in distilled water and $0.2 \mathrm{mmol}$ tantalum chloride precursor was dissolved in a concentrated methanol solution for $5 \mathrm{~min} .5 \mathrm{~mL}$ of Ta solution was dropped in niobium oxalate aqueous solution under magnetic stirring. After homogenization, $0.6 \mathrm{mmol}$ of $\mathrm{MnSO}_{4} \cdot 2 \mathrm{H}_{2} \mathrm{O}$ and $\mathrm{FeSO}_{4} \cdot 5 \mathrm{H}_{2} \mathrm{O}$ were added dropwise into the $\mathrm{Nb}$-Ta aqueous solution under continuous magnetic stirring for $1 \mathrm{~h}$. Then, the solution was transferred into a $50 \mathrm{~mL}$ stainless-steel Teflon lined autoclave and maintained at $200^{\circ} \mathrm{C}$ for $48 \mathrm{~h}$. The collected samples were centrifuged, washed with ethanol and distilled water, dried at $60^{\circ} \mathrm{C}$ for $24 \mathrm{~h}$, and finally annealed at $900^{\circ} \mathrm{C}$ for $3 \mathrm{~h}$. The synthesized sample named as WOCTs was used to compare with the extracted WOCT. 


\section{Physical and chemical characterization}

The chemical composition of the CT and WOCT was evaluated by the X-ray fluorescence spectroscopy (XRF, ZSX Primus II, Rigaku, Japan) and inductively coupled plasma mass spectrometry (ICP-MS, iCAP RQ, Thermo Fisher Scientific, USA). The multipurpose X-ray diffractometry (XRD, X'pert Pro, PANalytical, the Netherlands) with high-intensity monochromatic $\mathrm{Cu}-\mathrm{K} \alpha$ radiation as an incident beam $(\lambda=1.54 \AA)$ over a Bragg's angle ranging from 5 to $90^{\circ}$ was used to elucidate the presence of different peaks of the WOCT compared to the original CT material. The Brunauer-Emmett-Teller (BET, ASAP 2020, Micromeritics, USA) method was used to measure the specific surface area of the adsorbents using $\mathrm{N}_{2}$. The surface morphology was observed with a Field emission scanning electron microscopy-energy dispersive spectroscopy (FESEM-EDS, JSM-5900, JEOL, Japan). The elemental composition and their oxidation states in CT and WOCT were examined by X-ray photoelectron spectroscopy (XPS, Physical Electronics PHI 5400, USA) with AlK- $\alpha$ monochromatic X-ray source (hv $=1486.6 \mathrm{eV})$ at the spot size of $400 \mu \mathrm{m}$ in the diameter with charge compensation. The surface atomic arrangements were investigated by high-resolution transmission electron microscopy (HRTEM) on a JEM-ARM200F electron microscope equipped with a spherical aberration correction device (Cs corrected) for the objective lens. The shape, diffraction pattern, and crystal structure of WOCT were generated by transmitting electrons accelerated to $200 \mathrm{kV}$ through the thin samples $(<\sim 100$ $\mathrm{nm})$.

\section{Electrochemical measurement}

The electrochemical characterization was analyzed by Potentiostat/Galvanostat (ZIVE SP2, WonATech Co. Ltd., Seoul, Korea) with the conventional three-electrode electrochemical cell composed of WOCT, WOCTs, $\mathrm{Pt} / \mathrm{C}$, and $\mathrm{RuO}_{2} / \mathrm{C}$ deposited on the nickel foam $(1 \mathrm{~cm} \times 1 \mathrm{~cm})$ as a working electrode, graphite rod as a counter electrode, and the $\mathrm{Hg} / \mathrm{Hg}$ as a reference electrode (where the potential was converted in RHE by the ERHE $=\mathrm{EHg} / \mathrm{HgO}+0.098+0.059 \mathrm{pH}$ ). The measurement of the HER and OER polarization curves was conducted at the scan rate of $5 \mathrm{mV} \mathrm{s}^{-}$ ${ }^{1}$ and $1 \mathrm{M} \mathrm{KOH}$ at room temperature. The stability was studied at the $\mathrm{j}=-20$ and $10 \mathrm{mV} \mathrm{cm}^{-2}$ and the electrochemical impedance spectroscopy (EIS) was accomplished at an amplitude of $10 \mathrm{mV}$ and $0.054 \mathrm{~V}$ potential in a frequency range from $10^{5}$ to $10^{-2} \mathrm{~Hz}$. The cyclic voltammetry $(\mathrm{CV})$ was 
performed at different scan rates $\left(10\right.$ to $\left.100 \mathrm{mV} \mathrm{s}^{-1}\right)$ in the $-10 \mathrm{mV}$ to $-100 \mathrm{mV}$ vs. RHE region to calculate double-layer capacitance value $\left(\mathrm{C}_{\mathrm{dl}}\right)$ by plotting the $\Delta \mathrm{j}\left(\mathrm{j}_{\mathrm{a}}-\mathrm{j}_{\mathrm{c}}\right)$ at $0.98 \mathrm{~V}$ vs. RHE. The working electrode was prepared by dissolving $0.5 \mathrm{mg}$ of WOCT, WOCTs, $\mathrm{Pt} / \mathrm{C}$, and $\mathrm{RuO}_{2} / \mathrm{C}$ in 5 mL ethanol containing $20 \mu \mathrm{l}$ of Nafion ${ }^{\circledR} 115$ solution (5\%) sonicated for $10 \mathrm{~min}$. Then, the ink was drop-casted onto the surface of $3 \mathrm{D}$ nickel foam and dried at $60^{\circ} \mathrm{C}$ for $5 \mathrm{~h}$.

\section{Theoretical calculation}

The density functional theory (DFT) calculations were performed within the VASP -Vienna abInitio Simulation Package ${ }^{63-65}$. The electron-ion interactions were described using the projector augmented wave (PAW) pseudopotentials method ${ }^{66}$. The Perdew-Burke-Ernzerh (PBE) exchange correlation functional ${ }^{67}$ with Hubbard correction $(\mathrm{DFT}+\mathrm{U})$ for the on-site Coulomb Repulsion was used. In the present work, an effective $\mathrm{U}$ value of 3.0 for $\mathrm{Fe}, \mathrm{Mn} \mathrm{Ta}$, and $\mathrm{Nb}$ were found to provide an accurate description of the structural parameters and the electronic properties of $\mathrm{FeTa}_{2} \mathrm{O}_{6}$ and $(\mathrm{FeMn})(\mathrm{TaNb})_{2} \mathrm{O}_{6}$. All calculations were spin polarized. An energy cut-off of $500 \mathrm{eV}$ was used the expand the electronic wave functions, which is sufficient enough to converge the total energy and the Hellman-Feynman forces to within $10^{-6} \mathrm{eV}$ and $0.001 \mathrm{eV}^{-1}$, respectively. Van der Waals $(\mathrm{vdW})$ dispersion forces were accounted for using the Grimme DFT-D3 scheme ${ }^{68}$. A MonkhorstPack k-point mesh of $3 \times 9 \times 9$ and $3 \times 3 \times 1$ were used to sample Brillouin zone of the bulk materials and the (001) surface, respectively. The bulk FeTa2 $\mathrm{O}_{6}$ was modelled in the orthorhombic structure containing $4 \mathrm{Fe}, 8 \mathrm{Ta}$, and $24 \mathrm{O}$ ions. The replacement (substitution) of one Fe with $\mathrm{Mn}$ and one $\mathrm{Ta}$ with $\mathrm{Nb}$ resulted in the formation of $\mathrm{Fe}_{0.75} \mathrm{Mn}_{0.25} \mathrm{Ta}_{1.875} \mathrm{Nb}_{0.125} \mathrm{O}_{6}$, with the $\mathrm{Fe}^{2+}$ or $\mathrm{Mn}^{2+}$ ions occupying the A-sites, and $\mathrm{Nb}^{5+}$ or $\mathrm{Ta}^{5+}$ the $\mathrm{B}$-sites. The optimized structures and the corresponding unit cell parameters as given in Supplementary Fig. 8. The predicted most stable (100) surface (Supplementary Fig. 9) was used to characterize the HER and OER processes. To avoid interactions between periodic slabs, a vacuum size of $15 \AA$ was added in the z-direction. 


\section{References}

1 Gao, D. et al. Modular Design of Noble-Metal-Free Mixed Metal Oxide Electrocatalysts for Complete Water Splitting. Angew Chem Int Ed Engl 58, 4644-4648, doi:10.1002/anie.201900428 (2019).

2 Rong, H., Ji, S., Zhang, J., Wang, D. \& Li, Y. Synthetic strategies of supported atomic clusters for heterogeneous catalysis. Nature Communications 11, 5884, doi:10.1038/s41467-020-19571-6 (2020).

3 Guan, D. et al. Screening highly active perovskites for hydrogen-evolving reaction via unifying ionic electronegativity descriptor. Nat Commun 10, 3755, doi:10.1038/s41467-019-11847-w (2019).

4 Bion, N. \& Duprez, D. Water splitting as a tool for obtaining insight into metal-support interactions in catalysis. Comptes Rendus Chimie 19, 1326-1336, doi:10.1016/j.crci.2015.11.020 (2016).

5 Hunter, B. M., Gray, H. B. \& Muller, A. M. Earth-abundant heterogeneous water oxidation catalysts. Chemical reviews 116, 14120-14136 (2016).

6 Bergmann, A. et al. Reversible amorphization and the catalytically active state of crystalline Co 3 O 4 during oxygen evolution. Nature communications 6, 1-9 (2015).

7 Jin, H. et al. In situ cobalt-cobalt oxide/N-doped carbon hybrids as superior bifunctional electrocatalysts for hydrogen and oxygen evolution. Journal of the American Chemical Society 137, 2688-2694 (2015).

8 Smith, R. D. et al. Photochemical route for accessing amorphous metal oxide materials for water oxidation catalysis. Science 340, 60-63 (2013).

9 Tang, C. et al. Catalysis: Spatially Confined Hybridization of Nanometer-Sized NiFe Hydroxides into Nitrogen-Doped Graphene Frameworks Leading to Superior Oxygen Evolution Reactivity (Adv. Mater. 30/2015). Advanced Materials 27, 4524-4524 (2015).

10 Swesi, A. T., Masud, J. \& Nath, M. Nickel selenide as a high-efficiency catalyst for oxygen evolution reaction. Energy \& Environmental Science 9, 1771-1782 (2016).

11 Stern, L., Feng, L., Song, F. \& Hu, X. Energy Environ. Sci., 2015, 8, 2347-2351. CrystEngComm (2017).

12 Ryu, J. et al. 5, 4066-4074; j) YR Zheng, MR Gao, Q. Gao, HH Li, J. Xu, ZY Wu, SH Yu. Small 11, 182-188 (2015).

13 Zheng, Y. et al. Toward design of synergistically active carbon-based catalysts for electrocatalytic hydrogen evolution. ACS nano 8, 5290-5296 (2014).

14 Zheng, Y. et al. Hydrogen evolution by a metal-free electrocatalyst. Nature communications 5, 18 (2014).

15 Kim, J. S., Kim, B., Kim, H. \& Kang, K. Recent progress on multimetal oxide catalysts for the oxygen evolution reaction. Advanced Energy Materials 8, 1702774 (2018).

16 Chen, Z., Duan, X., Wei, W., Wang, S. \& Ni, B.-J. Recent advances in transition metal-based electrocatalysts for alkaline hydrogen evolution. Journal of Materials Chemistry A 7, 14971-15005, doi:10.1039/C9TA03220G (2019).

17 Yu, J., Le, T. A., Tran, N. Q. \& Lee, H. Earth-Abundant Transition-Metal-Based Bifunctional Electrocatalysts for Overall Water Splitting in Alkaline Media. Chemistry - A European Journal 26, 6423-6436, doi:https://doi.org/10.1002/chem.202000209 (2020).

$18 \mathrm{Qu}$, M. et al. Regulating electron density of NiFe-P nanosheets electrocatalysts by a trifle of Ru for high-efficient overall water splitting. Applied Catalysis B: Environmental 263, 118324 (2020).

19 Nikolov, I. et al. Electrocatalytic activity of spinel related cobalties $\mathrm{MxCo} 3-\mathrm{xO} 4(\mathrm{M}=\mathrm{Li}, \mathrm{Ni}, \mathrm{Cu})$ in the oxygen evolution reaction. Journal of Electroanalytical Chemistry 429, 157-168 (1997). 
$\mathrm{Hu}$, C. et al. Synergism of geometric construction and electronic regulation: 3D Se-(NiCo) $\mathrm{Sx} /(\mathrm{OH})$ $\mathrm{x}$ nanosheets for highly efficient overall water splitting. Advanced Materials 30, 1705538 (2018).

21 Lin, J. et al. S doped NiCo2O4 nanosheet arrays by Ar plasma: an efficient and bifunctional electrode for overall water splitting. Journal of colloid and interface science 560, 34-39 (2020).

22 Zhu, C., Fu, S., Du, D. \& Lin, Y. Facilely Tuning Porous NiCo2O4 Nanosheets with Metal Valence-State Alteration and Abundant Oxygen Vacancies as Robust Electrocatalysts Towards Water Splitting. Chemistry-A European Journal 22, 4000-4007 (2016).

23 Fang, L. et al. Crystal-plane engineering of NiCo2O4 electrocatalysts towards efficient overall water splitting. Journal of catalysis 357, 238-246 (2018).

24 Deliormanl1, A. M. \& Konyal1, R. Correction to: Bioactive glass/hydroxyapatite-containing electrospun poly( $\varepsilon$-caprolactone) composite nanofibers for bone tissue engineering. Journal of the Australian Ceramic Society 55, 621-621, doi:10.1007/s41779-018-0242-z (2018).

25 Dutta, S., Pal, S. \& De, S. Mixed solvent exfoliated transition metal oxides nanosheets based flexible solid state supercapacitor devices endowed with high energy density. New Journal of Chemistry 43, 12385-12395, doi:10.1039/c9nj03233a (2019).

26 Eftekhari, A. Electrocatalysts for hydrogen evolution reaction. International Journal of Hydrogen Energy 42, 11053-11077, doi:10.1016/j.ijhydene.2017.02.125 (2017).

27 Endrődi, B. et al. Selective Hydrogen Evolution on Manganese Oxide Coated Electrodes: New Cathodes for Sodium Chlorate Production. ACS Sustainable Chemistry \& Engineering 7, 1217012178, doi:10.1021/acssuschemeng.9b01279 (2019).

28 Fang, L. et al. Crystal-plane engineering of NiCo2O4 electrocatalysts towards efficient overall water splitting. Journal of Catalysis 357, 238-246, doi:10.1016/j.jcat.2017.11.017 (2018).

29 Rodriguez, M. H., Rosales, G. D., Pinna, E. G. \& Suarez, D. S. Extraction of niobium and tantalum from ferrocolumbite by hydrofluoric acid pressure leaching. Hydrometallurgy 156, 17-20, doi:10.1016/j.hydromet.2015.05.006 (2015).

30 Somarin, A. K. Geochemical Fingerprinting of Conflict Minerals Using Handheld XRF: An Example for Coltan, Cassiterite, and Wolframite Ores from Democratic Republic of the Congo, Africa. Minerals 9, doi:10.3390/min9090564 (2019).

31 Feng, Y., Liang, T., Yang, X., Zhang, Z. \& Wang, Y. Chemical Evolution of Nb-Ta Oxides and Cassiterite in Phosphorus-Rich Albite-Spodumene Pegmatites in the Kangxiwa-Dahongliutan Pegmatite Field, Western Kunlun Orogen, China. Minerals 9, doi:10.3390/min9030166 (2019).

32 Nete, M., Purcell, W. \& Nel, J. T. Separation and isolation of tantalum and niobium from tantalite using solvent extraction and ion exchange. Hydrometallurgy 149, 31-40, doi:10.1016/j.hydromet.2014.06.006 (2014).

33 Ohmori, H., Shibata, J., Sano, M. \& Nishimura, S. Extraction of Niobium and Tantalum with Bis2-Ethylhexyl Acetamide. Solvent Extraction and Ion Exchange 5, 227-243, doi:10.1080/07366298708918563 (1987).

34 Purcell, W., Potgieter, H., Nete, M. \& Mnculwane, H. Possible methodology for niobium, tantalum and scandium separation in ferrocolumbite. Minerals Engineering 119, 57-66, doi:10.1016/j.mineng.2018.01.031 (2018).

$35 \mathrm{Wu}$, C.-C. \& Yang, C.-F. Effect of V2O5 B-site substitution on the microstructure, Raman spectrum, and dielectric properties of SrBi2Ta2O9 ceramics. Scientific Reports 10, 19147, doi:10.1038/s41598-020-73327-2 (2020).

36 Shimakawa, Y. et al. Crystal structure and ferroelectric properties of $\$ \mathrm{~A}\{\operatorname{lmathrm}\{\mathrm{Bi}\}\}_{-}\{2\}\{\backslash \operatorname{mathrm}\{\mathrm{Ta}\}\}_{-}\{2\}\{\backslash \operatorname{mathrm}\{\mathrm{O}\}\}_{-}\{9\}(\mathrm{A}=\mid \operatorname{mathrm}\{\mathrm{Ca}\}, \$ \mathrm{Sr}$, and $\mathrm{Ba})$. Physical Review B 61, 6559-6564, doi:10.1103/PhysRevB.61.6559 (2000).

37 Van Lichtervelde, M., Holtz, F. \& Melcher, F. The effect of disequilibrium crystallization on NbTa fractionation in pegmatites: Constraints from crystallization experiments of tantalite-tapiolite. American Mineralogist 103, 1401-1416, doi:10.2138/am-2018-6441 (2018). 
Primc, D. et al. Doping of TiO2 as a tool to optimize the water splitting efficiencies of titaniahematite photoanodes. Sustainable Energy \& Fuels 1, 199-206, doi:10.1039/c7se00005g (2017).

39 Kan, W. H., Chen, M., Bae, J.-S., Kim, B.-H. \& Thangadurai, V. Determination of Fe oxidation states in the $\mathrm{B}$-site ordered perovskite-type $\mathrm{Ba} 2 \mathrm{Ca} 0.67 \mathrm{Fe} 0.33 \mathrm{NbO} 6-\delta$ at the surface (nano-scale) and bulk by variable temperature XPS and TGA and their impact on electrochemical catalysis. Journal of Materials Chemistry A 2, doi:10.1039/c4ta00811a (2014).

40 Yang, L. et al. A Novel Ultra-Sensitive Semiconductor SERS Substrate Boosted by the Coupled Resonance Effect. Adv Sci (Weinh) 6, 1900310, doi:10.1002/advs.201900310 (2019).

41 Kong, L.et al. Nanoarchitectured Nb2O5 hollow, Nb2O5@carbon and NbO2@ carbon Core-Shell Microspheres for Ultrahigh-Rate Intercalation Pseudocapacitors. Sci Rep 6, 21177, doi:10.1038/srep21177 (2016).

42 Baubet, B. et al. Quantitative Two-Dimensional (2D) Morphology-Selectivity Relationship of CoMoS Nanolayers: A Combined High-Resolution High-Angle Annular Dark Field Scanning Transmission Electron Microscopy (HR HAADF-STEM) and Density Functional Theory (DFT) Study. ACS Catalysis 6, 1081-1092, doi:10.1021/acscatal.5b02628 (2016).

43 Blom, D. A., Li, X., Mitra, S., Vogt, T. \& Buttrey, D. J. STEM HAADF Image Simulation of the Orthorhombic M1 Phase in the Mo-V-Nb-Te-O Propane Oxidation Catalyst. ChemCatChem 3, 1028-1033, doi:https://doi.org/10.1002/cctc.201100049 (2011).

44 Dachraoui, W. et al. Short-Range Layered A-Site Ordering in Double Perovskites NaLaBB'O6(B $\left.=\mathrm{Mn}, \mathrm{Fe} ; \mathrm{B}^{\prime}=\mathrm{Nb}, \mathrm{Ta}\right)$. Chemistry of Materials 23, 2398-2406, doi:10.1021/cm200226u (2011).

45 Rhatigan, S., Michel, M.-C. \& Nolan, M. Hydrogen evolution on non-metal oxide catalysts. Journal of Physics: Energy 2, doi:10.1088/2515-7655/aba3bc (2020).

46 McCrory, C. C. L. et al. Benchmarking Hydrogen Evolving Reaction and Oxygen Evolving Reaction Electrocatalysts for Solar Water Splitting Devices. Journal of the American Chemical Society 137, 4347-4357, doi:10.1021/ja510442p (2015).

47 Jaramillo, T. F. et al. Identification of Active Edge Sites for Electrochemical H\&lt;sub\&gt;2\&lt;/sub\&gt; Evolution from MoS\&lt;sub\&gt;2\&lt;/sub\&gt; Nanocatalysts. Science 317, 100, doi:10.1126/science.1141483 (2007).

48 McCrory, C. C. L., Jung, S., Peters, J. C. \& Jaramillo, T. F. Benchmarking Heterogeneous Electrocatalysts for the Oxygen Evolution Reaction. Journal of the American Chemical Society 135, 16977-16987, doi:10.1021/ja407115p (2013).

49 Greeley, J., Jaramillo, T. F., Bonde, J., Chorkendorff, I. \& Nørskov, J. K. Computational highthroughput screening of electrocatalytic materials for hydrogen evolution. Nature materials $\mathbf{5}, 909$ 913 (2006).

50 Nørskov, J. K. et al. Trends in the exchange current for hydrogen evolution. Journal of The Electrochemical Society 152, J23 (2005).

$51 \mathrm{Wu}, \mathrm{L}$. et al. Unraveling the role of Lithium in enhancing the hydrogen evolution activity of MoS2: intercalation versus adsorption. ACS energy letters 4, 1733-1740 (2019).

52 Ojha, K., Saha, S., Dagar, P. \& Ganguli, A. K. Nanocatalysts for hydrogen evolution reactions. Physical Chemistry Chemical Physics 20, 6777-6799 (2018).

53 McCrory, C. C. et al. Benchmarking hydrogen evolving reaction and oxygen evolving reaction electrocatalysts for solar water splitting devices. Journal of the American Chemical Society 137, 4347-4357 (2015).

54 Jiao, Y., Zheng, Y., Jaroniec, M. \& Qiao, S. Z. Design of electrocatalysts for oxygen-and hydrogeninvolving energy conversion reactions. Chemical Society Reviews 44, 2060-2086 (2015).

55 Rossmeisl, J., Logadottir, A. \& Nørskov, J. K. Electrolysis of water on (oxidized) metal surfaces. Chemical physics 319, 178-184 (2005). 
56 Skúlason, E. et al. Modeling the electrochemical hydrogen oxidation and evolution reactions on the basis of density functional theory calculations. The Journal of Physical Chemistry C 114, 18182-18197 (2010).

57 Rodríguez, O. et al. Recovery of niobium and tantalum by solvent extraction from $\mathrm{Sn}-\mathrm{Ta}-\mathrm{Nb}$ mining tailings. RSC Advances 10, 21406-21412, doi:10.1039/d0ra03331f (2020).

58 McNeil, A. G., Linnen, R. L. \& Flemming, R. L. Hydrothermal Synthesis of Columbite-(Mn), Tantalite-(Mn), Hafnon, and Zircon At $800-850{ }^{\circ} \mathrm{C}$ and $200 \mathrm{MPa}$. The Canadian Mineralogist 53, 1073-1081, doi:10.3749/canmin.1400077 (2016).

59 Lei, S. et al. Preparation and magnetic and microwave absorption properties of $\mathrm{MnNb} 2 \mathrm{O} 6$ ellipsoid-like hierarchical structures. CrystEngComm 16, 7949-7955, doi:10.1039/C4CE00652F (2014).

60 Lei, S. et al. Synthesis and magnetic properties of $\mathrm{MNb} 2 \mathrm{O} 6(\mathrm{M}=\mathrm{Fe}, \mathrm{Co}, \mathrm{Ni})$ nanoparticles. $R S C$ Advances 4, 52740-52748, doi:10.1039/C4RA08269A (2014).

61 Joya, M., Barba Ortega, J., Raba Paez, A., da Silva Filho, J. \& Cavalcante Freire, P. Synthesis and Characterization of Nano-Particles of Niobium Pentoxide with Orthorhombic Symmetry. Metals 7, doi:10.3390/met7040142 (2017).

62 Toure, M., Arrachart, G., Duhamet, J. \& Pellet-Rostaing, S. Tantalum and Niobium Selective Extraction by Alkyl-Acetophenone. Metals 8, doi:10.3390/met8090654 (2018).

63 Berner, R. A. Tetragonal iron sulfide. Science 137, 669-669 (1962).

64 Kresse, G. \& Joubert, D. From ultrasoft pseudopotentials to the projector augmented-wave method. Physical review b 59, 1758 (1999).

65 Kresse, G. \& Furthmüller, J. Efficient iterative schemes for ab initio total-energy calculations using a plane-wave basis set. Physical review B 54, 11169 (1996).

66 Blöchl, P. E. Projector augmented-wave method. Physical review B 50, 17953 (1994).

67 Perdew, J. P., Burke, K. \& Ernzerhof, M. Generalized gradient approximation made simple. Physical review letters 77, 3865 (1996).

68 Grimme, S., Antony, J., Ehrlich, S. \& Krieg, H. A consistent and accurate ab initio parametrization of density functional dispersion correction (DFT-D) for the 94 elements H-Pu. The Journal of chemical physics 132, 154104 (2010). 


\section{Acknowledgments}

This work was supported by the National Research Foundation of Korea (NRF) grant funded by the Korea government (MSIT)(2019R1A2C1003988). Also partially supported from the Regional Leading Research Center Program (2019R1A5A8080326) through the National Research Foundation funded by the Ministry of Science and ICT of Republic of Korea. NYD acknowledges the UK Engineering and Physical Sciences Research Council (EPSRC) for funding (Grant No. EP/S001395/1). The computational resources used are the Advanced Research Computing at Cardiff (ARCCA) Division, Cardiff University, and HPC Wales and ARCHER

(http://www.archer.ac.uk), the UK's national supercomputing service, via the membership of the UK's HEC Materials Chemistry Consortium, which is funded by EPSRC (EP/L000202).

\section{Author contributions}

P.M.B. Experiments design, physical and electrochemical characterizations, C.C. and J.P. carry out the synthesis experiments, E.O.A. helped on the electrochemical data analysis, N.Y.D and D.H.K. performed the theoretical calculations, C.H.P. and C.S.K. directed, supervised the planning and the funding of this research. All the authors contributed on the manuscript redaction.

\section{Competing interests}

The authors report no declarations of interest. 


\section{Figures}
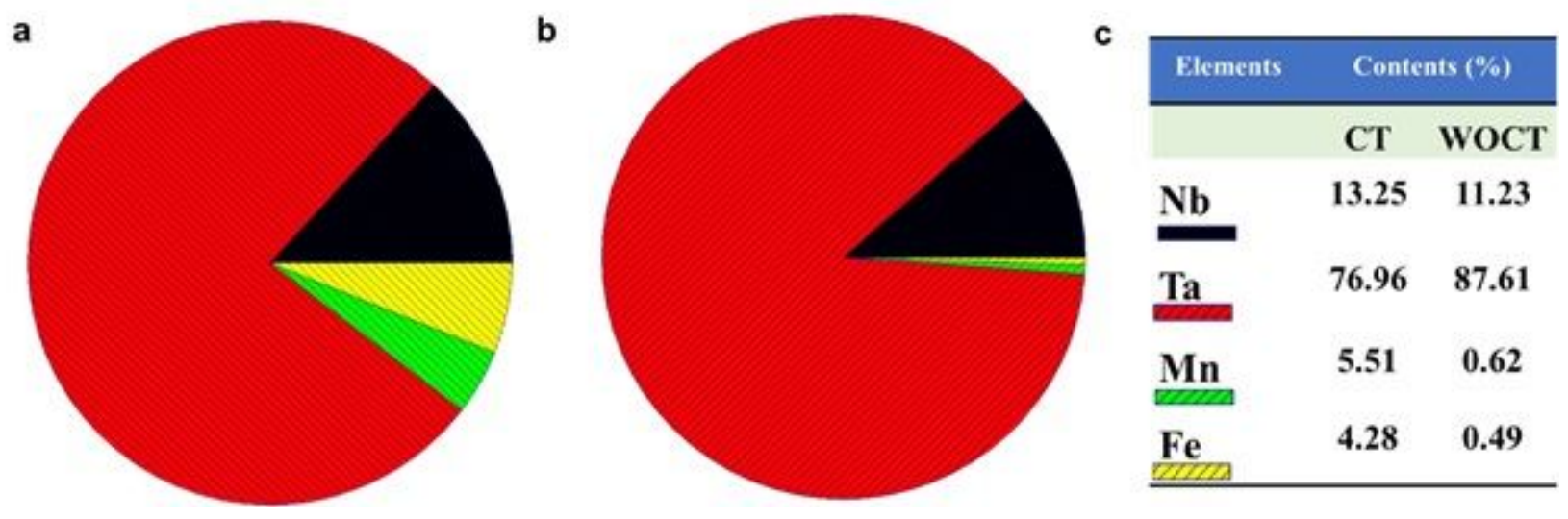

Figure 1

Compositional analysis. Pie chart of niobium, tantalum, manganese and iron contents in (a) CT, (b) WOCT and (c) table of correspondent percentage (amount: $0.02 \mathrm{~g}$, volume: $50 \mathrm{~mL}$, and dilution factor: 100 times).
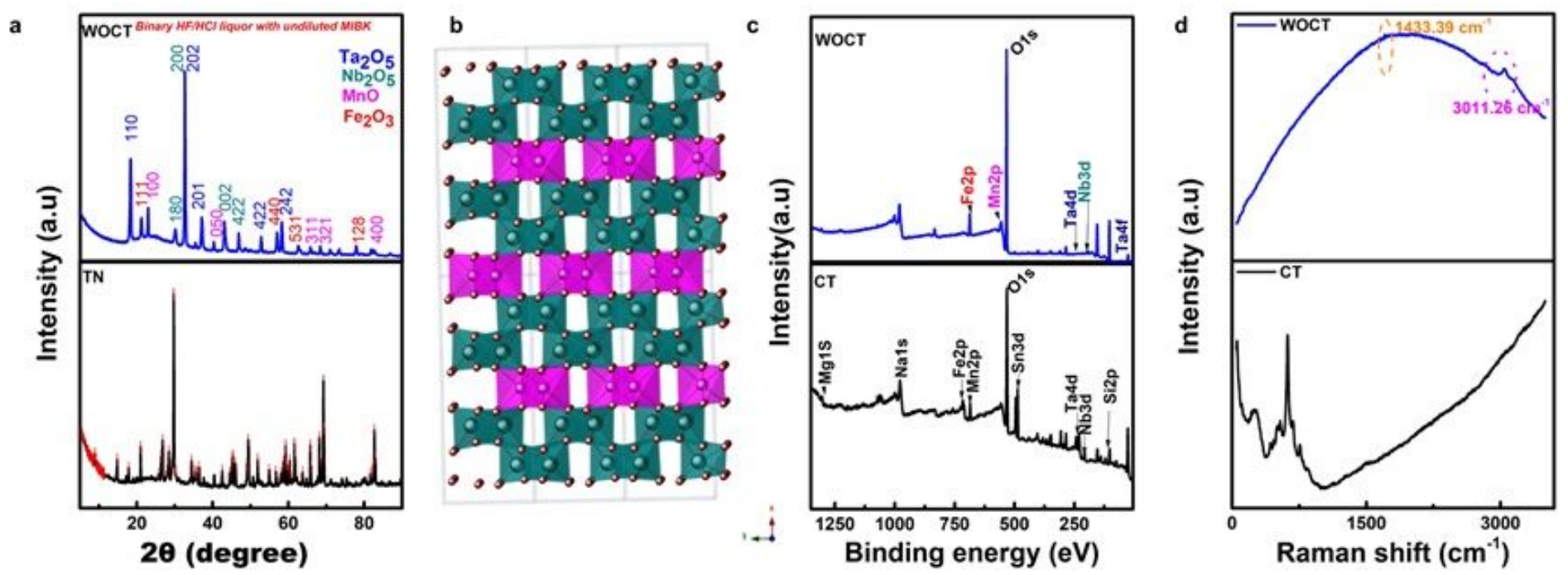

Figure 2

Structure characterization. (a) XRD pattern, (b) typical AB206 columbo-tantalite structure, A and B elements transition metal ( $\mathrm{A}=\mathrm{Fe}, \mathrm{Mn}$ and with $\mathrm{B}=\mathrm{Ta}, \mathrm{Nb})$ in Pbcn group octahedrally coordinated to the oxygen atoms), (c) XPS survey, and (d) Raman spectra of the CT and WOCT samples. 

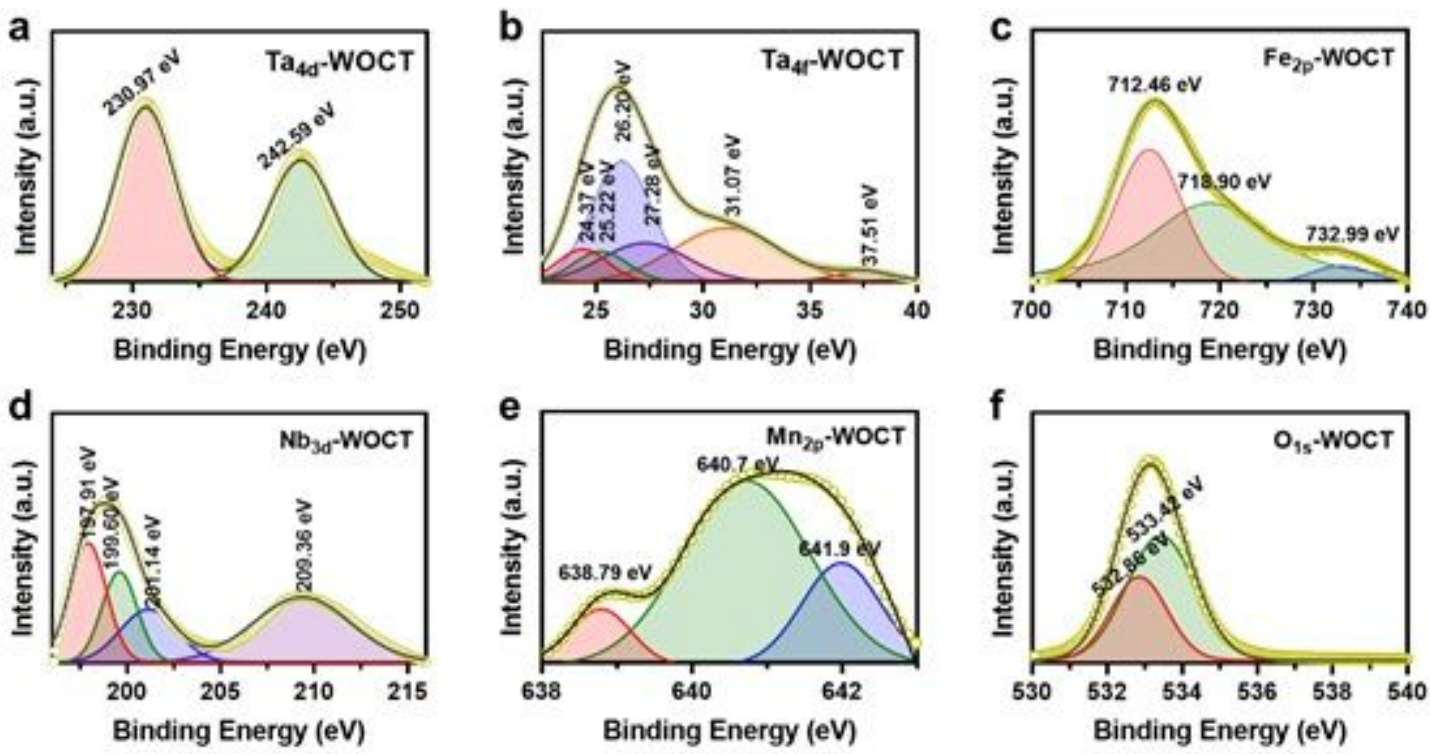

Figure 3

Chemical structure analysis of catalysts. (a-f): X-ray photoelectron spectroscopy (XPS) of WOCT of the Ta4d, Ta4f, Fe2p, Nb3d, Mn2p, and 01s, peaks. Fitted curves are shown in black and normalized curves are in pea green. Peak intensities are shown for clarification.

a

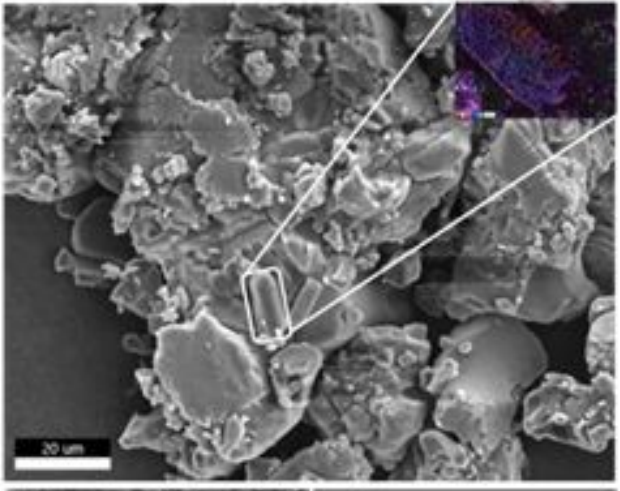

b

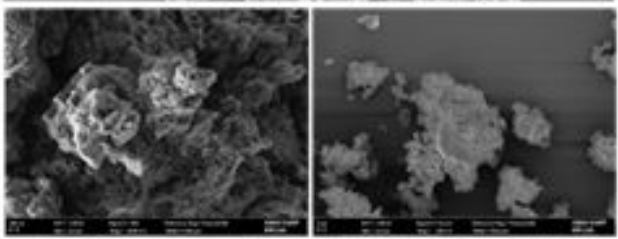

c

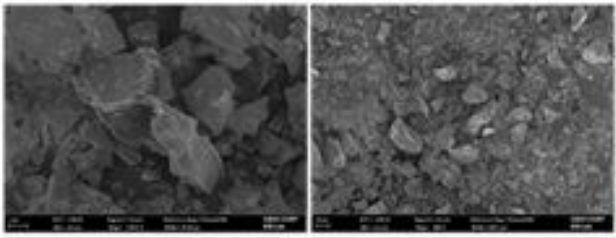

d

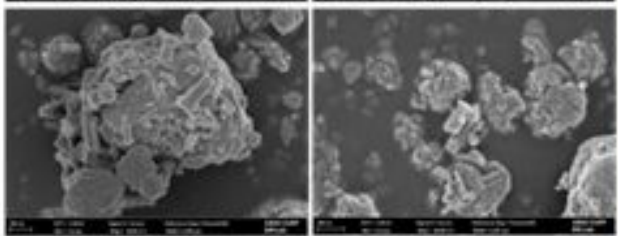

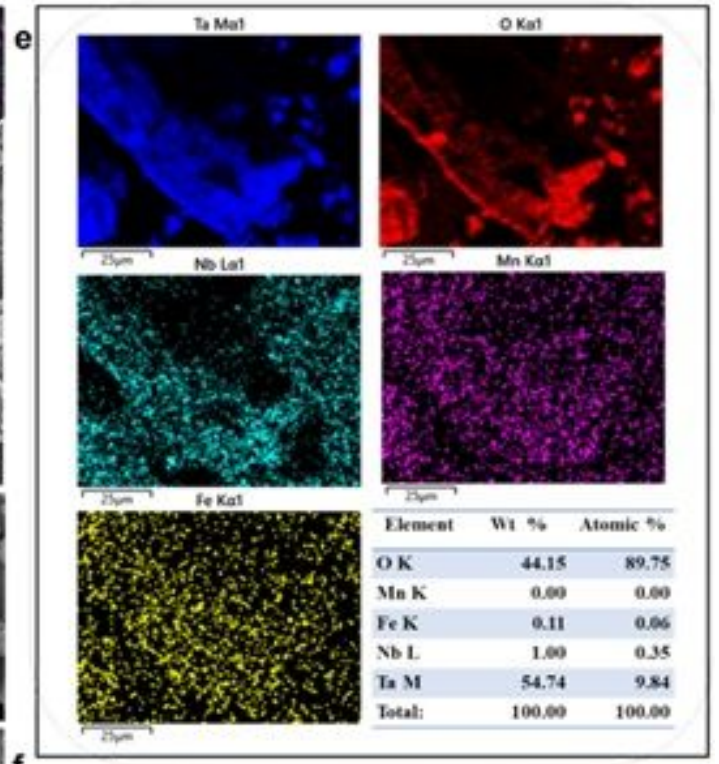

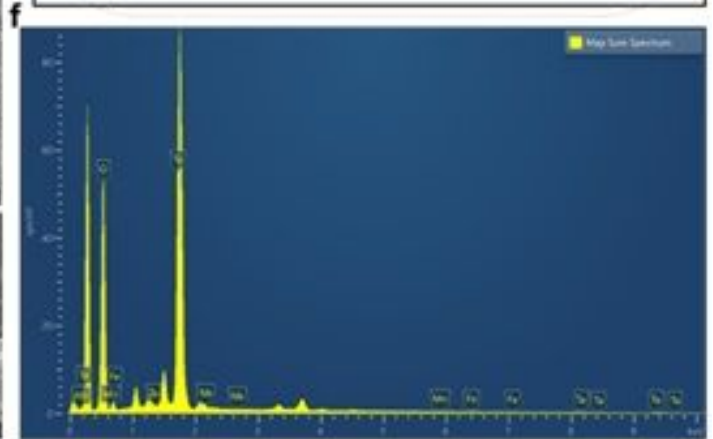

Figure 4 
Morphology and elemental mapping characterization of catalysts. (a-d) External morphology of WOCT, WOCT-135, WOCT-1050 and WOCTs. (e) WOCT FESEM image with elements mapping (O, Nb, Mn, Fe, and Ta). (f) Energy dispersive x-ray spectroscopy (EDS) analysis of WOCT.

a

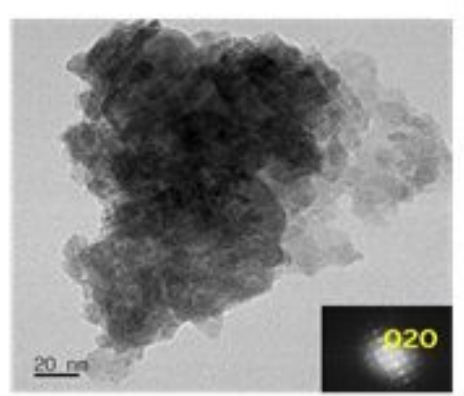

b

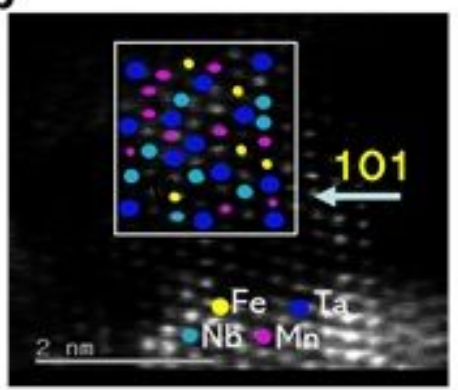

d
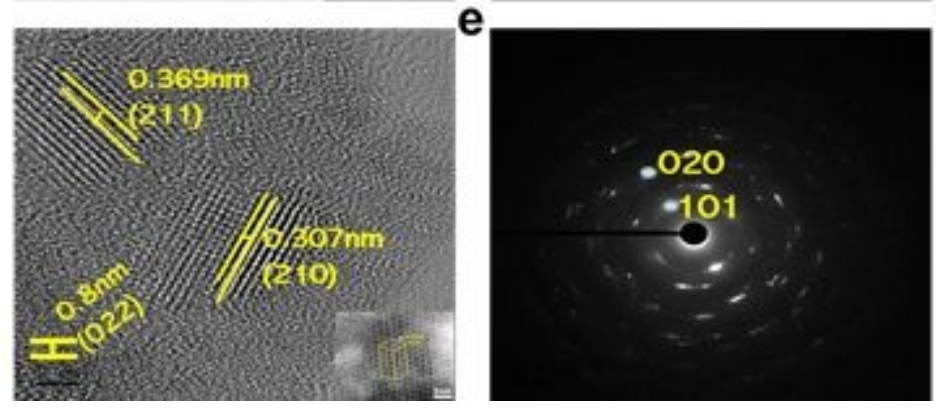

C

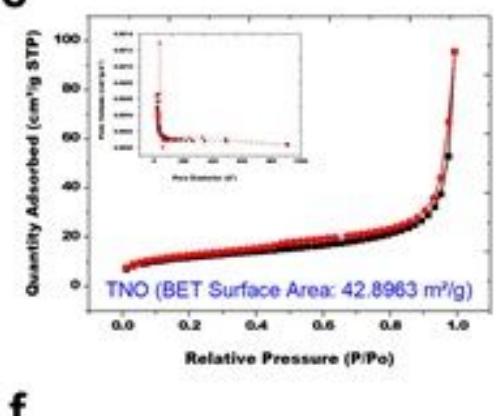

f

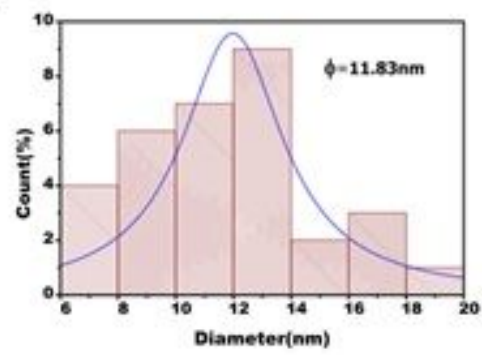

\section{Figure 5}

Microstructural characterization of catalysts. (a) TEM image of WOCT (Inset: diffraction pattern taken under the (020) and (101) zone axis). (b) Selective HAADF-STEM of WOCT taken close to the (101) zone axis with $\mathrm{Ta}, \mathrm{Nb}, \mathrm{Mn}$, and Fe overlaid atoms. (c) HRTEM image (Inset: a structural model of the threefold superstructure) and (d) the selected area electron diffraction (SAED) of WOCT. (e) Nitrogen adsorptiondesorption isotherms (Inset: corresponding pore size distributions) of WOCT extracted by the binary acid $\mathrm{HF} / \mathrm{HCl}$ ). (f) Histogram of WOCT particles distribution where the average particle size equals $11.83 \mathrm{~nm}$. 

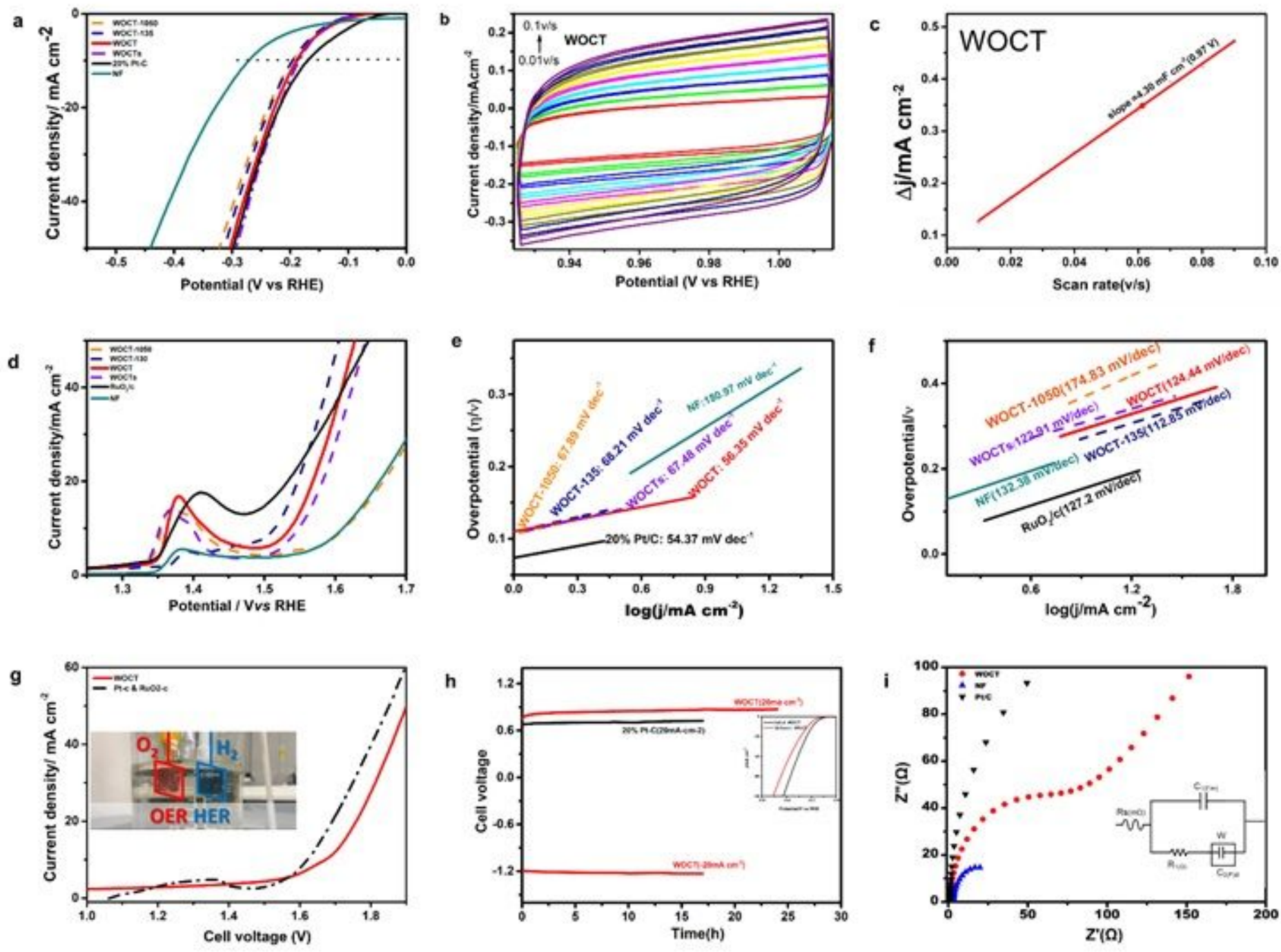

Figure 6

Fundamental electrochemical relationships measured for HER and OER on catalysts. (a) Linear sweep voltammograms (LSV) curves measured in $1 \mathrm{M} \mathrm{KOH}$ at a scan rate of $5 \mathrm{mV} \mathrm{s}-1$. (b) Cyclic voltammograms. (c) charging current density differences $(\Delta \mathrm{j}=\mathrm{ja}-\mathrm{jc})$ as a function of the scan rate, $\mathrm{Cdl}$ obtained by the $\mathrm{Cv}$ at $0.97 \mathrm{v} \mathrm{Hg} / \mathrm{HgO}$. (d) OER-LSV polarization curves. (e-f) corresponding Tafel plot of HER and OER. (g) LSV comparing the water -splitting performance of WOCT and Pt/C \& RuO2/C (inset image of electrolyzer step for overall water splitting). (h) Durability test of WOCT and Pt/C evaluated at $\mathrm{j}=$ -20 and 20 mA cm-2 (inset: HER-LSV shows the initial and after 24 hours). (i) Electrochemical impedance spectroscopy (EIS) of WOCT and Pt/C (inset image is an analog circuit diagram). 


\section{$\mathrm{FeTa}_{2} \mathrm{O}_{6}(100)$}

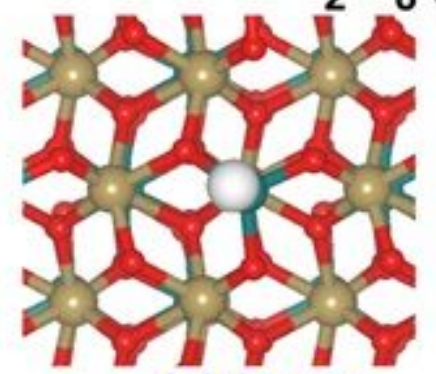

(a) *Fe-p

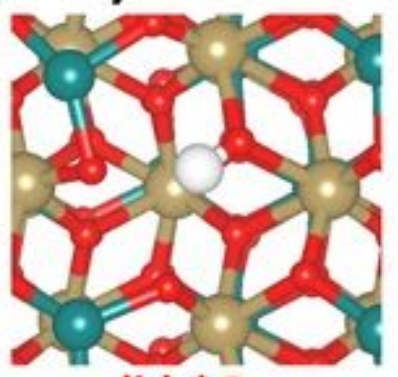

(b) *0-p $\odot \mathrm{Fe}$

Mn

○Ta

$\mathrm{Nb}$

$\odot \mathrm{O}$

$\mathrm{H}$

\section{$(\mathrm{Fe}, \mathrm{Mn})(\mathrm{Nb}, \mathrm{Ta})_{2} \mathrm{O}_{6}(100)$}

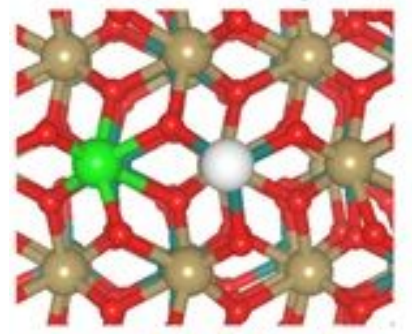

(c) *Fe-d

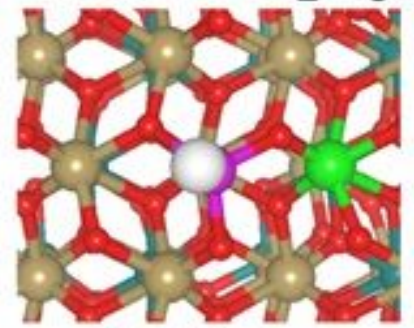

(d) *Mn-d

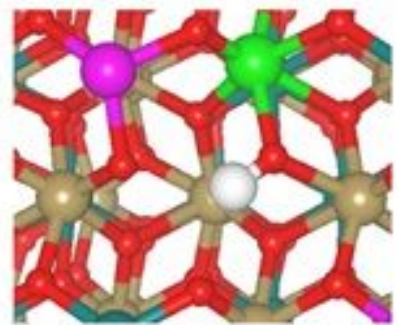

(e) * O-d

Figure 7

DFT characterization of $\mathrm{H}$ adsorption structures. Adsorption structures of $\mathrm{H}$ (HER intermediate) on pure (a \& b) FeTa2O6 and on doped (c-e) Fe0.75Mn0.25Ta1.875Nb0.12506 (100) surfaces. 
(a)

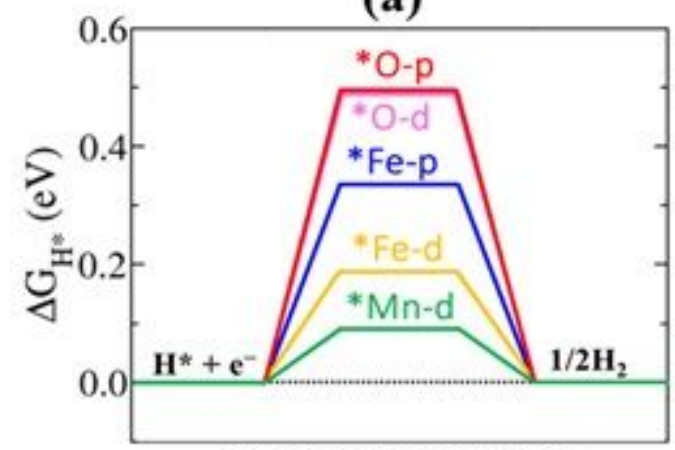

Reaction coordinate

(c)

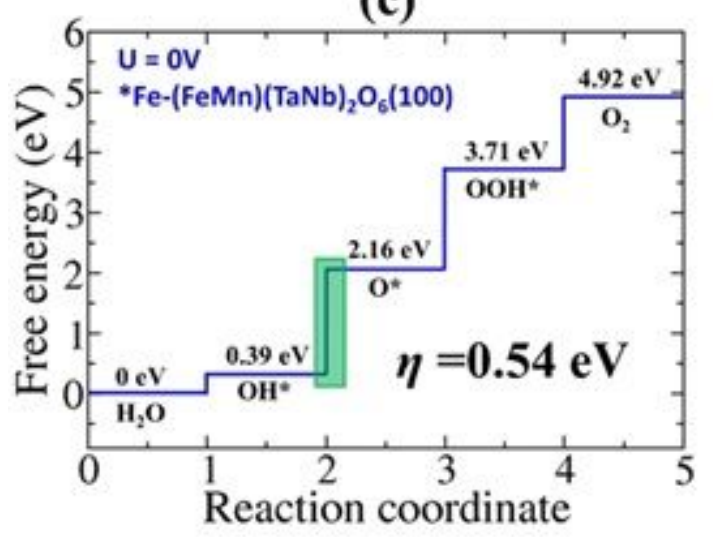

(e)

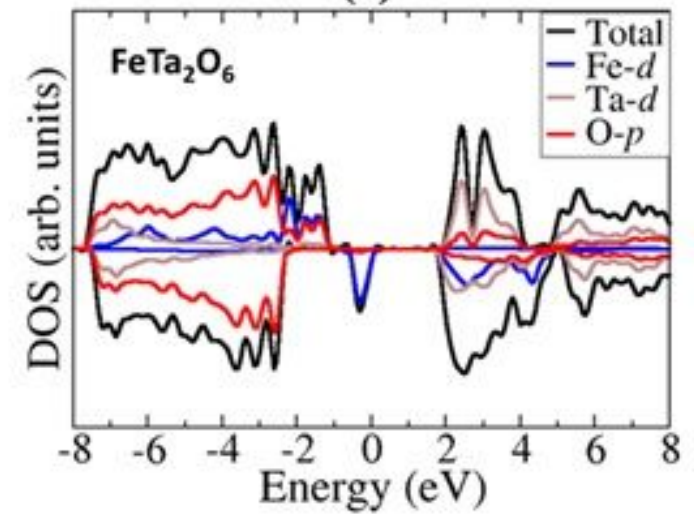

(b)

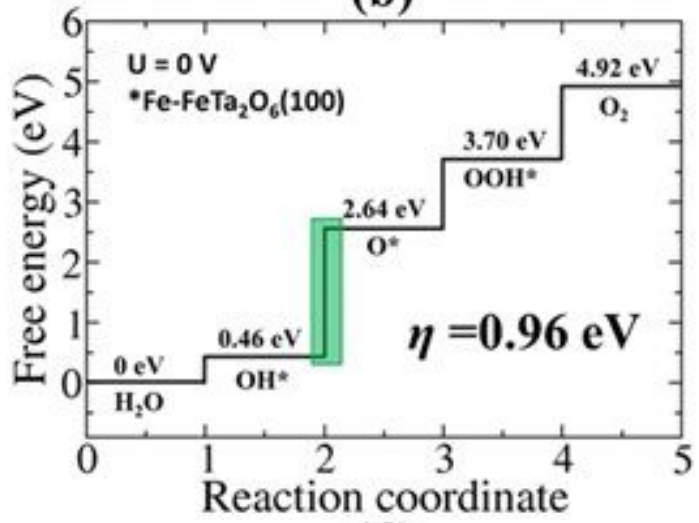

(d)

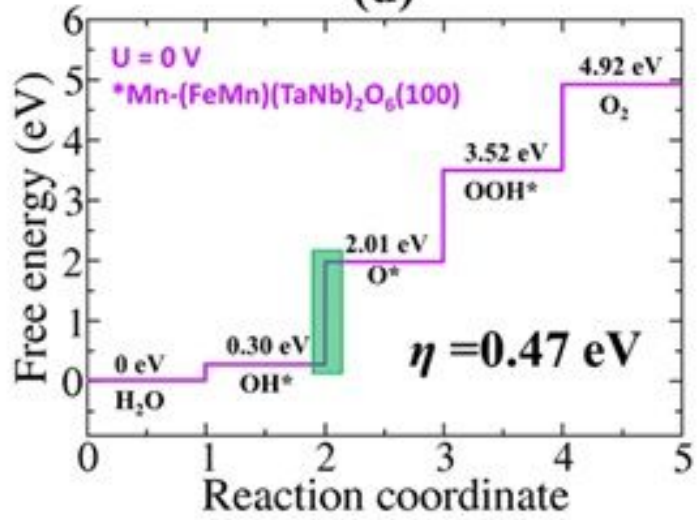

(f)

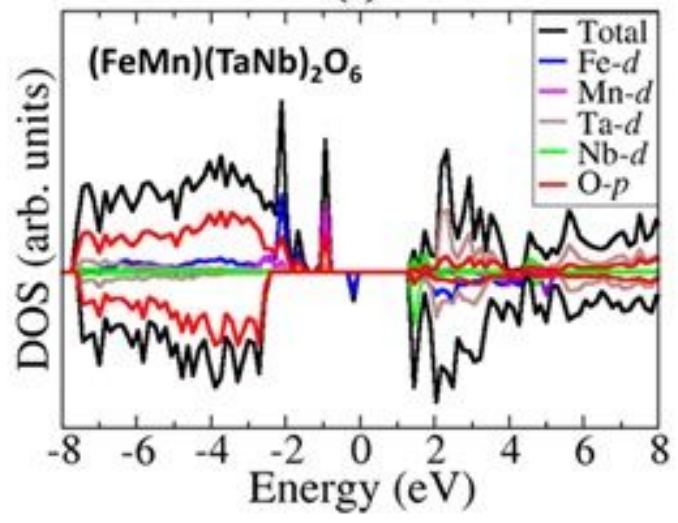

Figure 8

DFT calculation for the HER and OER mechanism. (a) Gibbs free energy of hydrogen adsorption ( $\left.\Delta \mathrm{GH}^{*}\right)$ at different possible active sites on pure-p FeTa2O6(100) and doped-d Fe0.75Mn0.25Ta1.875Nb0.12506(100). Gibbs free-energy diagram for four steps of OER on (b) Fe site at FeTa2O6(100) (c) Fe site at Fe0.75Mn0.25Ta1.875Nb0.12506(100) and (d) Mn site on Fe0.75Mn0.25Ta1.875Nb0.12506(100). The marked green box denotes the rate determining step and $\eta$ is the overpotential. (e) and (f) are the elecronic partial density of states (PDOS) for pure FeTa2O6 and dope $\mathrm{Fe} 0.75 \mathrm{Mn} 0.25 \mathrm{Ta} 1.875 \mathrm{Nb} 0.12506$ materials. 
(a) ${ }^{*} \mathrm{Fe}-\mathrm{FeTa}_{2} \mathrm{O}_{6}(100)$

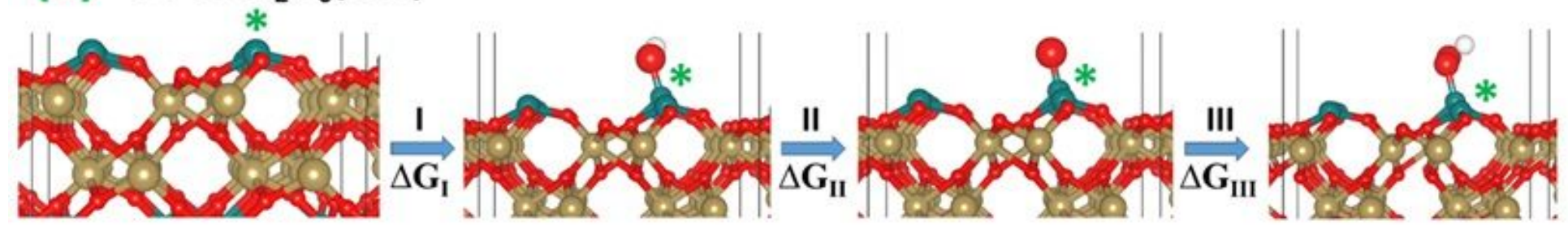

(b) $* \mathrm{Fe}-(\mathrm{FeMn})(\mathrm{TaNb})_{2} \mathrm{O}_{6}(\mathbf{1 0 0})$

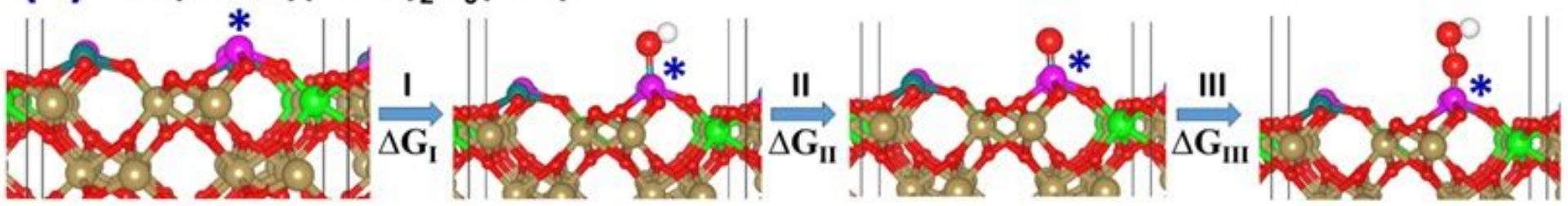

$(\mathrm{c}) * \mathrm{Mn}-(\mathrm{FeMn})(\mathrm{TaNb})_{2} \mathrm{O}_{6}(\mathbf{1 0 0})$

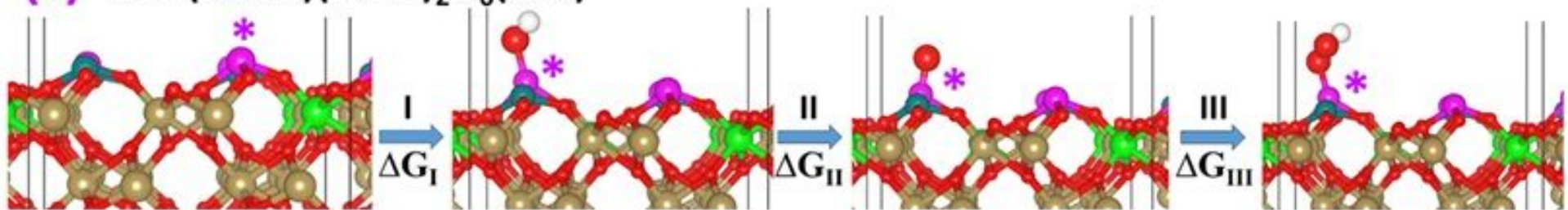

$\odot$ Fe $\odot$ mn $\odot \mathbf{T a} \bigcirc \mathbf{N b} \odot \mathbf{O} \bigcirc$

Figure 9

DFT characterization of OER intermediates. Optimised adsorption structures of OER intermediates $\left({ }^{\star} \mathrm{OH}\right.$, ${ }^{*}$, and ${ }^{*} \mathrm{OOH}$ ) at (a) Fe-site on FeTa2O6(100), (b) at Fe-site and (c) at Mn-site at doped Fe0.75Mn0.25Ta1.875Nb0.12506 (100).

\section{Supplementary Files}

This is a list of supplementary files associated with this preprint. Click to download.

- Supplementaryinformations.docx

- watersplittingcell.mp4

- GraphicalAbstract.jpg 